
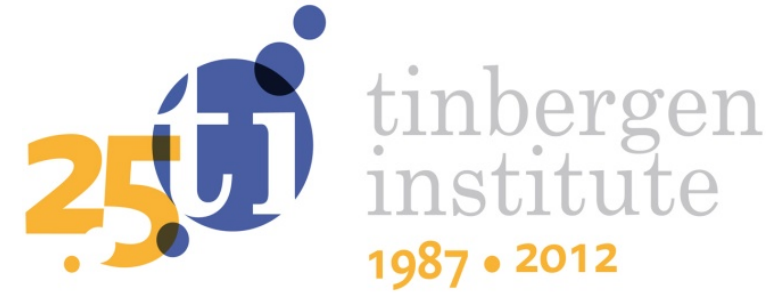

\title{
Rising Inequalities in Income and Health in China: \\ Who is left behind?
}

Steef Baeten ${ }^{1,2}$

Tom Van Ourtil,3

Eddy van Doors/aerl,3

' Erasmus University Rotterdam;

2 Institute for Health Policy and Management;

3 Erasmus School of Economics, and Tinbergen Institute. 
Tinbergen Institute is the graduate school and research institute in economics of Erasmus University Rotterdam, the University of Amsterdam and VU University Amsterdam.

More TI discussion papers can be downloaded at http://www.tinbergen.nl

Tinbergen Institute has two locations:

Tinbergen Institute Amsterdam

Gustav Mahlerplein 117

1082 MS Amsterdam

The Netherlands

Tel.: +31(0)205251600

Tinbergen Institute Rotterdam

Burg. Oudlaan 50

3062 PA Rotterdam

The Netherlands

Tel.: +31(0)10 4088900

Fax: $+31(0) 104089031$

Duisenberg school of finance is a collaboration of the Dutch financial sector and universities, with the ambition to support innovative research and offer top quality academic education in core areas of finance.

DSF research papers can be downloaded at: http://www.dsf.nl/

Duisenberg school of finance

Gustav Mahlerplein 117

1082 MS Amsterdam

The Netherlands

Tel.: +31(0)20 5258579 


\title{
Rising inequalities in income and health in China: Who is left behind?
}

\author{
Steef Baeten ${ }^{\mathrm{a}}$, Tom Van Ourti ${ }^{\mathrm{b},{ }^{*}}$, Eddy van Doorslaer ${ }^{\mathrm{a}, \mathrm{b}}$ \\ ${ }^{a}$ Institute for Health Policy and Management, Erasmus University Rotterdam, P.O. Box 1738, 3000 DR \\ Rotterdam, the Netherlands \\ ${ }^{b}$ Erasmus School of Economics, Erasmus University Rotterdam, P.O. Box 1738, 3000 DR Rotterdam, the \\ Netherlands; Tinbergen Institute, and NETSPAR
}

June 13, 2012

\begin{abstract}
During the last decades, China has experienced double-digit economic growth rates and rising inequality. This paper implements a new decomposition on the China Health and Nutrition panel Survey (1991-2006) to examine the extent to which changes in level and distribution of incomes and in income mobility are related to health disparities between rich and poor. We find that health disparities in China relate to rising income inequality and in particular to the adverse health and income experience of older (wo)men, but not to the growth rate of average incomes over the last decades. These findings suggest that replacement incomes and pensions at older ages may be one of the most important policy levers in combating health disparities between rich and poor Chinese.
\end{abstract}

KEY WORDS: China, income growth, income inequality, income mobility, health inequality JEL Classification Number: C00, D30, D63, I14, 115

*Corresponding author. Tel: +31 10 4082170; fax: +31 104089141

E-mail addresses: baeten@bmg.eur.nl (Steef Baeten); vanourti@ese.eur.nl (Tom Van Ourti); vandoorslaer@ese.eur.nl (Eddy van Doorslaer). 


\section{Introduction}

The relationship between income and health, and the inequality in each of these, has been documented in many settings, but few countries have experienced changes in their income distribution as dramatic and as rapid as China has over the last few decades. China's rapid transition since the early 1980s from a completely planned economy to a more market led economy has led to unprecedented economic growth: China's real GDP in 2009 was more than the twelvefold of its real GDP in 1980. Poverty reductions were similarly spectacular: between 1981 and 2005 the poverty headcount ratio ( $\$ 1.25$ poverty line) fell from $94 \%$ to $26 \%$ in rural areas and from $44 \%$ to $2 \%$ in urban areas (World Bank, 2005). The income distribution has not only shifted upward, it has also substantially widened, leading to rising inequality in incomes (Benjamin et al., 2008) both within and between regions.

However, this rapid economic growth did not spark equally impressive health improvements (Tang et al., 2008). While, for instance, average life expectancy has continued to grow, China has lost its high achiever position. The Chinese average life expectancy is not any longer higher than expected on the basis of average income, indicating that the pace of health gains has slowed down. Moreover, health disparities between urban and rural regions and between rich and poor have grown and have given rise to increased public dissatisfaction. The Chinese government has recognized these challenges and has responded to them. Reform of health care has been ongoing for several years and in 2008 the Ministry of Health announced major new policy directions for achieving Healthy China by 2020 (Tang et al., 2008). These reforms have somewhat alleviated the health burdens faced by the (rural) poor, but concerns remain (Hougaard et al., 2011; Wagstaff et al., 2009b). At the same time, China has experienced several other demographic and economic transitions. The population is rapidly growing older, becoming more urbanized and economic activity has shifted from largely agricultural to industrial. A priori, it is not obvious how these dramatic changes in the Chinese society have influenced the relation between (changes in) income, health, their distributions and the health gaps between rich and poor.

One way of uncovering the mechanics underlying these relationships is to decompose the (changes in the) degree of income-related health inequality (IRHI). Contoyannis and Forster (1999) initiated the examination of conditions under which increases in income and income inequality will be associated with higher levels of IRHI as measured by a rank-based concentration index. Van Ourti et al. (2009) have generalized their argument using a cohort decomposition approach and have used it to examine inequalities in health by income in European countries in the 1990s. In this paper, we propose an extension and simplification of their decomposition framework to uncover these mechanics in China. The simplification derives from recognizing that health - unlike income - is a bounded variable at the upper end and using an adjusted rank-based measure of absolute inequality. The extension consists of the addition of an additional component relating to income mobility which proves to be crucial for an improved understanding of the evolution of IRHI. We then apply this framework to an analysis of inequalities in self-reported health by income in a cohort followed over 6 waves of the China Health and Nutrition Survey (CHNS) panel and spanning a period of 15 years (1991-2006).

We find that the degree to which health is associated to income - as measured by a rankbased measure of absolute inequality - more than tripled over those 15 years. This substantive rise turns out to be not related to the massive income growth and only weakly to the growth in income inequality. It is almost entirely explained by the very different income mobility by age and gender. Especially the much more adverse experience of older females in terms of their income position and health seems to have been important. The 
absence of adequate replacement incomes for sick and old women, especially in rural areas, is a likely candidate to explain this phenomenon.

In the next section we briefly review what is known on income and health developments in China since the start of the economic reforms. In section 3 we discuss our new decomposition framework which is then applied to Chinese panel data spanning the period 1991-2006 in section 4. We conclude with a discussion of potential implications.

\section{Income, health and inequality in China}

China is no different from any other country in exhibiting inequalities in income and health and a strong association between the two. What makes China more unique is (i) the pace of changes in recent decades and (ii) the sheer size of the country reflecting such immense differences in levels of development. The rapid growth in average incomes in China has been accompanied by an increase in income inequality. While initially, income inequality was at a fairly low level (Kanbur and Zhang, 2005), the transition from a planned to a more market oriented economy has dramatically increased variability in incomes (Gustafsson et al., 2008; Lin et al., 2008; Shen and Yao, 2008; Sutherland and Yao, 2011; Yang, 1999), wealth (Gustafsson et al., 2006) and consumption (Keidel, 2009). Initially, rising income inequality was not viewed as unacceptable, because the initial income distribution was relatively egalitarian and because it reduced absolute levels of poverty in society. Moreover, high income mobility was perceived as a blessing because it meant that poor households were not trapped in their situation (Khor and Pencavel, 2010), but more recently discontent about the widening gaps has been growing (Yu, 2008).

Developments in nationwide income inequality obviously mask important geographic differentials. Two geographic distinctions appear particularly relevant in this respect. A first important geographic division of China is that between eastern provinces near the coast and the western non-coast provinces. Historically the eastern coastal regions have had higher levels of GDP than the interior regions (Chen and Fleisher, 1996). More recently, the coastal provinces have coupled a stronger rise in mean per capita income with a more modest increase in income inequality compared to the interior regions (Benjamin et al., 2008). While the growth of the inter-regional inequality was anticipated by the government, which favored the coastal provinces in the early years of the reforms, the spillovers to other regions were insufficient to reduce the initial inter-regional income inequality (Brun et al., 2002).

A second geographic divide is that between rural and urban areas. Large urban-rural disparities in income have persisted for a long time, among others due to the introduction of the labor-mobility restricting Hukou system (Wang and Piesse, 2010), and to welfare and financial policies that favored the urban areas (Yang, 1999). This inequality between rural and urban areas contributes substantially to total income inequality in China, and is rapidly growing (Yang, 1999) such that China's urban-rural income gap is now one of the largest in the world (Chang, 2002; Sicular et al., 2007). Within-urban and within-rural income inequality are currently of similar magnitude (Sutherland and Yao, 2011).

Several studies have documented health variation by income and region in China. For example, (Liu et al., 2008) report an income gradient in self-reported health in rural areas, while (Chen and Meltzer, 2008) report income gradients for hypertension and obesity. Other studies have documented substantial health variation by region, e.g. life expectancy between and within provinces (Tang et al., 2008), infant mortality between and within inland 
and coastal regions (Zhang and Kanbur, 2005) and between rural and urban areas (Shi et al., 2008), or self-reported health between rural and urban areas (Van de Poel et al., 2012).

Fewer studies have measured trends in IRHI. Chen et al. (2007) use the China Health and Nutrition Survey to find that child malnutrition was concentrated among the poor in 1989, that this concentration decreased in the early nineties but rose again in 2000. Using the same data, Yip (2010) does not find these inequalities to have either widened or narrowed. Wagstaff et al. (2009a) use data from the maternal and child health $(\mathrm{MCH})$ surveillance system of 2003 and report large inequalities in infant, under-five and maternal deaths across counties. Recently, Feng et al. (2010) examined the evolution of socio-economic disparities in maternal mortality by county (ranked by income) between 1996 and 2006 in the $\mathrm{MCH}$. They also do not find a clear trend in the concentration indices.

Overall, we conclude that (i) there is enormous variation in China in both the level and distribution of income and health, (ii) which are associated across place and time and (iii) no study has yet attempted to trace out how developments of income growth, income inequality and income mobility are related to income-related health inequality developments over the recent decades.

\section{Decomposing income-related health inequalities into income growth, mean- preserving income changes and income mobility}

We measure income-related health inequalities by the variation of health across the income dimension (Erreygers, 2009a; Wagstaff and van Doorslaer, 2000) and summarize its association with the income distribution using a decomposition methodology (Wagstaff et al., 2003). Since this paper explicitly focuses on the exceptional income growth rates that China experienced over the last three decades, we isolate the role of changes in average incomes from other changes in the income distribution. To this end, we extend the decomposition method proposed by Van Ourti et al. (2009) such that it accounts for the bounded nature of health (Erreygers and Van Ourti, 2011a). We also provide a new interpretation of this decomposition that stresses the role of income mobility.

\subsection{Measurement of income-related health inequalities}

$\mathrm{IRHI}$ is most commonly measured using the standard concentration index. It resembles a Gini index of health, but replaces the rank of health by the rank of income such that it measures the variation of health across the income dimension (Wagstaff et al., 1991). An important implicit value judgment is that equi-proportionate health changes leave the concentration index unchanged. This is a common assumption in the uni-dimensional income inequality literature (Lambert, 2001), but recent work shows that this focus on relative health differences is less innocuous in the case of bi-dimensional IRHI (Erreygers, 2009a; Erreygers, 2009b; Erreygers and Van Ourti, 2011b; Erreygers and Van Ourti, 2011a; Lambert and Zheng, 2011; Wagstaff, 2009; Wagstaff, 2011a; Wagstaff, 2011b). When health has a finite upper and lower bound (as in our empirical application) an impossibility result arises: relative health differences are incompatible with the requirement that income-related inequalities in health and ill-health should rank a set of health-income distributions in the same way. We put more emphasis on the latter requirement since the transformation from health to illhealth, i.e. ill-health equals maximum health minus actual health, is arbitrary and does not change the information contained in the health (or ill-health) variable. It follows that we can no longer resort to the concentration index that focuses on relative health differences, but instead use the Erreygers index (2009a) which indicates that IRHI remains unchanged under equal health additions: 


$$
C_{E}(h \mid y)=\frac{8}{n^{2}\left(h^{\max }-h^{\min }\right)} \sum_{i=1}^{n} z_{i} h_{i}=\frac{8}{n^{2}} \sum_{i=1}^{n} z_{i} h_{i}
$$

where $h_{i}$ equals the level of health of individual $i^{1}, y_{i}$ equals income, and $n$ stands for the number of observations. $z_{i}$ equals the deviation of individuals $i$ 's income rank from the mean income rank' ${ }^{2}$; and increases linearly between $(1-n) / 2$ and $(n-1) / 2$ and takes zero for the individual with the mean income rank. In other words, the $z_{i}^{\prime}$ s are negative for the poorest half of the population and positive for the richest half, and sum to zero across the entire population. Hence, the Erreygers index will be negative if the poor have overall better health than the rich (pro-poor IRHI), and positive values will imply the opposite (pro-rich IRHI).

\subsection{Changes in the income distribution and IRHI: a decomposition approach}

Our approach extends the approach of Van Ourti et al. (2009) in two ways. First, we simplify their decomposition by measuring IRHI with the Erreygers index. This simplification is the logical consequence of the change of focus from relative to absolute health differences, as it no longer requires to understand how changes in the income distribution are related to average health levels, which is indispensable to understand relative health differences. Second, we show that the decomposition is richer than originally envisaged by the authors. Van Ourti et al. (2009) isolate the role of changes in average incomes from other changes in the income distribution, but we show that this implies that IRHI also depend on the association between income mobility and the evolution in other determinants of health.

Our extended decomposition is a cohort-decomposition, i.e. it unravels how IRHI evolves over time for a given cohort of individuals such that we can abstract from changes in IRHI that are driven by compositional changes of the underlying population. We show later in this section that our cohort-decomposition also isolates the ageing-effect of our cohort such that we can study the change of IRHI over time in isolation from ageing. We assume in this section that individuals remain in the cohort over the entire time period, but we allow for drop-out in the empirical part of the paper. In the remainder of this section, we discuss our extended decomposition in more detail.

We start by describing the association between health and income $y_{i}$ conditional on a set of $K$ other variables $x_{i}$ (e.g. age, sex) and add a time subscript $t=1, \ldots, T$.

$$
h_{i t}=\alpha+\phi\left(y_{i t}\right)+x_{i t}{ }^{\prime} \beta
$$

$\phi(\cdot)$ is a (non-linear) function of income, $\alpha$ is a parameter, and $\beta$ is a parameter vector of dimension $K$. As the shape of the function $\phi(\cdot)$ will largely determine the association between the evolution of IRHI and changes in the income distribution (see below), we allow for a very general functional form.

Three simplifying assumptions underlie equation (2). In the empirical part of the paper, we confirm that these assumptions are justified. First, we rule out interactions between the non-linear function of income $\phi(\cdot)$ and the set of other variables $x_{i}$. Second, we assume that

\footnotetext{
${ }^{1}$ We assume in equation (1) without loss of generality that health is bounded between $0\left(h^{\min }\right)$ and $1\left(h^{\max }\right)$ as any bounded variable can be retransformed to the unit interval.

${ }^{2} z_{i}=\frac{n+1}{2}-\lambda_{i}$, and the income rank $\lambda_{i}$ takes the value 1 for the richest individual and $n$ for the poorest individual.
} 
the coefficients in equation (2) are fixed over time which has the advantage that changes in IRHI are associated to changes in the explanatory variables only (and not to changes in the coefficients). Finally, equation (2) ignores dynamics. Note also that we exclude a residual term from equation (2) for ease of exposition.

We express the evolution of IRHI as the difference between the Erreygers index in period $t$ and the first period, and substitute equation (2) in equation (1):

$$
C_{E}\left(h_{t} \mid y_{t}\right)-C_{E}\left(h_{1} \mid y_{1}\right)=\frac{8}{n^{2}} \sum_{i=1}^{n}\left\{\left[z_{i t} \phi\left(y_{i t}\right)-z_{i 1} \phi\left(y_{i 1}\right)\right]+\sum_{k=1}^{k} \beta^{k}\left[z_{i t} x_{i t}^{k}-z_{i 1} x_{i 1}^{k}\right]\right\}
$$

Equation (3) provides us with a decomposition of the evolution of IRHI into those related to changes in the income distribution (i.e. the first term between square brackets) and into those due to changes in other determinants, weighted by the respective $z_{i}$ 's (i.e. the second term between square brackets); it does not, however, allow to separate the effect of proportional income growth from other changes in the income distribution. Van Ourti et al. (2009) disentangle both effects by introducing two hypothetical health states in period $t$. The first is the situation of 'proportional income growth' $(p g)$ in which total income growth benefits everyone proportionately such that individual incomes grow at the same rate as average income $\left(Y_{t}\right)$, i.e. $h_{i t}^{p g}=\alpha+\phi\left(y_{i t}^{p g}\right)+x_{i t}{ }^{\prime} \beta$ with $y_{i t}^{p g}=y_{i 1}\left(Y_{t} / Y_{1}\right)$. Secondly, we introduce a health state in which income 'does not grow' $(n g)$, but the other variables evolve at their actual rate, i.e. $h_{i t}^{n g}=\alpha+\phi\left(y_{i 1}\right)+x_{i t}{ }^{\prime} \beta .^{3}$

We have now sufficient information to derive our extended decomposition:

$$
\left.\begin{array}{rl}
C_{E}\left(h_{t} \mid y_{t}\right)-C_{E}\left(h_{1} \mid y_{1}\right) & =\underbrace{\left[C_{E}\left(h_{t} \mid y_{t}\right)-C_{E}\left(h_{t}^{p g} \mid y_{1}\right)\right]}_{(2) \&(3)}+\underbrace{\left[C_{E}\left(h_{t}^{p g} \mid y_{1}\right)-C_{E}\left(h_{t}^{n g} \mid y_{1}\right)\right]}_{(4)} \\
& +\underbrace{\left[C_{E}\left(h_{t}^{n g} \mid y_{1}\right)-C_{E}\left(h_{1} \mid y_{1}\right)\right]}_{(1)} \\
& =\frac{8}{n^{2}}\{\underbrace{\sum_{i=1}^{n} z_{i 1}\left[\phi\left(y_{i t}^{p g}\right)-\phi\left(y_{i 1}\right)\right]}_{(3)}+\underbrace{\sum_{i=1}^{n}\left[z_{i t} \phi\left(y_{i t}\right)-z_{i 1} \phi\left(y_{i t}^{p g}\right)\right]}_{(2)}]
\end{array}\right\}
$$

which exploits that $C_{E}\left(h_{t}^{p g} \mid y_{t}^{p g}\right) \equiv C_{E}\left(h_{t}^{p g} \mid y_{1}\right)$ and $y_{i t}^{n g} \equiv y_{i 1}$. Equation (4) shows that we can decompose the evolution of IRHI into four effects: (i) a term related to income growth; (ii) a term related to other mean-preserving changes in the income distribution; (iii) a term related to differences in income mobility across non-income variables; and (iv) a term related to the association between changes in the other variables and $z_{i}$ in the first period.

\section{Income growth}

Term (1) in equation (4) captures the association between the evolution of IRHI and average income growth. It describes the difference between IRHI in the hypothetical health state in which all individuals would have had their incomes changed proportionately and IRHI in the

\footnotetext{
${ }^{3}$ Note that the introduction of the hypothetical health states is 'path-independent', i.e. it does not matter for our decomposition whether we have the sequence $h_{i 1} \rightarrow h_{i t}^{n g} \rightarrow h_{i t}^{p g} \rightarrow h_{i t}$ or $h_{i 1} \rightarrow h_{i 1}^{p g} \rightarrow h_{i t}^{p g} \rightarrow h_{i t}$, since we combine the Erreygers index - which only focuses on absolute health differences - with equation (2) - which is additively separable in $\phi\left(y_{i t}\right)$ and $x_{i t}{ }^{\prime} \beta$.
} 
state in which incomes would have remained at the level of the first period. Recalling that the $z_{i t}$ 's sum to zero and increase linearly when moving from the poorest to the richest individual is sufficient to understand that a positive/negative value of term (1) will occur when $\phi\left(y_{i t}^{p g}\right)-\phi\left(y_{i 1}\right)$ is 'on average' increasing/decreasing with income. Intuitively this means that IRHI will rise/decrease when the same proportional income change has a larger/smaller health effect for individuals with a higher initial income. ${ }^{4}$ Whether and how this relationship between health and proportional income increases varies with income will depend on the shape of $\phi(\cdot)$. This highlights the importance of choosing a flexible functional form for income in equation (2), rather than - as is usual in the literature - sticking to a functional form (like e.g. the natural logarithm) that predetermines how the health effect of proportional income changes varies with income.

\section{Other mean-preserving changes in the income distribution}

Term (2) in equation (4) measures the change in IRHI associated with changes in the distribution of income that are unrelated to proportional income growth. It combines changes from $z_{i 1}$ to $z_{i t}$ (which are a function of the income ranks) with mean-preserving changes in the income levels from $y_{i t}^{p g}$ to $y_{i t}$. When the income ranks do not change over time, the health impact of the change in income levels will depend on the functional form of $\phi(\cdot)$ and on the extent to which income gains and losses differ across income groups. When richer individuals have higher income gains than poorer individuals (a pro-rich change) and when proportional income increases have a larger health effect for individuals with higher incomes, IRHI will rise (and vice versa). When both effects have the opposite sign (e.g. higher health effect of a proportional income change for richer individuals combined with a propoor change), it is an empirical question which effect dominates. In practice, income ranks will also change, but we cannot a priori predict the effect on IRHI without knowing the realized changes in income ranks. However, it seems likely that the change in income ranks will in most cases be independent or coincide with the pro-poor- or pro-richness of the change of income levels (but generally not be in the opposite direction). ${ }^{5}$

\section{Income mobility across non-income variables}

Term (3) in equation (4) illustrates that the evolution in IRHI is also driven by the association between the non-income variables in equation (2) and changes in the income ranks. Its interpretation depends on the sign of $\beta^{k}$, which measures the health effect of the nonincome variables. When this effect is positive, all that is needed to increase IRHI is that those already experiencing better health because of the non-income variables, e.g. the young, move up in the income distribution, i.e. $z_{i t}>z_{i 1}$. When the health effect is negative, the opposite result holds. In other words, this term identifies the contribution of differences in

${ }^{4} \phi\left(y_{i t}^{p g}\right)-\phi\left(y_{i 1}\right)$ will only 'on average' increase/decrease with income when its partial derivative with respect to $y_{i 1}$ is positive, i.e. when $\partial\left[\phi\left(y_{i t}^{p g}\right)-\phi\left(y_{i 1}\right)\right] / \partial y_{i 1}=0 \Leftrightarrow\left[\partial \phi\left(y_{i t}^{p g}\right) / \partial y_{i t}^{p g}\right] Y_{t}=\left[\partial \phi\left(y_{i 1}\right) / \partial y_{i 1}\right] Y_{1}$. $\leq \quad \leq$

${ }^{5}$ An implicit assumption so far has been that we conceive IRHI as being invariant to equal health additions and the subdivision of changes in the income distribution along a relative concept (i.e. proportional income growth versus 'other mean-preserving changes'). Our choice for equal health additions is the logical consequence of using the Erreygers index (see also before), and we find it also very plausible to define income growth as a relative concept. However, those who favor absolute income inequality concepts might find a definition of income growth where every individual gains the same amount of income more plausible. The sum of term (1) and (2) will not be affected by this alternative assumption and it is straightforward to adapt terms (1) and (2). 
income mobility across the non-income variables to IRHI (Allanson et al., 2010; Jones and Nicolás, 2004).

Similar to other decomposition methods (Fortin et al., 2011), the interpretation of term (3) is more complicated when $x_{i t}$ includes dummy variables representing categorical variables. First, $\beta^{k} x_{i t}^{k}$ measures in that case the health effect of a change in the dummy from 0 to 1 . Second, the choice of the reference category (e.g. whether we take males or females as the reference category) matters for the contribution of each dummy variable, but does not matter for the sum across all dummy variables. ${ }^{6}$ This means that the contribution of a separate dummy should be interpreted with respect to the reference group.

\section{Changes in other variables and initial income ranks}

Finally, term (4) shows that the evolution of IRHI is also determined by the way in which changes in other non-income variables are related to $z_{i 1}$ (which is a function of the income rank in the first period). For example, when age is included in $x_{i t}$, term (4) will indicate whether the health effect of getting older $\left(\beta^{\text {age }}\left(x_{i t}^{a g e}-x_{i 1}^{a g e}\right)\right)$ is related to the initial income rank. In other words, it will isolate the ageing of our cohort from the evolution of IRHI over time.

Summing up, our approach decomposes the evolution of IRHI in four elements and builds on a regression linking health to income and other non-income variables. The first two elements are related to the marginal income distribution only. First, equi-proportionate income growth is associated with rising IRHI when proportional income changes have larger health effects among those with higher incomes. Second, mean-preserving changes in the income distribution lead to rising IRHI when larger health effects from proportional income changes for the rich are combined with pro-rich changes in the income distribution. We re-emphasize that the importance of whether these health effects increase or decrease with income, makes it essential to allow for a flexible functional form of income. The two remaining elements of the decomposition are related to the interdependence between changes in the income distribution and changes in the non-income variables. We find that income mobility (i.e. individuals moving up the income rank) will lead to increasing IRHI when it disproportionally favors those who are already healthy (e.g. the young). We also show that changes in non-income variables only matter insofar as these are related to the initial income rank.

\section{Data and empirical implementation}

We use the China Health and Nutrition Survey (CHNS) to analyze the evolution of IRHI in China, and the extent to which it is associated with changes in the Chinese income distribution. The CHNS is an ongoing panel data set that covers nine different provinces of China. For details of the CHNS we refer to the project website (Carolina Population Center, 2010).

\subsection{Estimating the relation between health, income and non-income variables}

Our measure of individual health is based on the four possible responses to a self-reported health (SAH) question. In all waves, individuals were asked "Right now, how would you describe your health compared to that of other people of your age?": Excellent, Good, Fair

\footnotetext{
${ }^{6}$ The sum of the associations between the dummy variables and the change in income ranks across all $L$ categories (including the reference category) equals zero since $\sum_{k=1}^{L} x_{i t}^{k}=1$, i.e. $\sum_{k=1}^{L-1} \sum_{i} x_{i t}^{k}\left(z_{i t}-z_{i 1}\right)=-\sum_{i} x_{i t}^{L}\left(z_{i t}-z_{i 1}\right)$.
} 
or Poor? ${ }^{7}$ These ordered responses are not suitable for measuring inequality with a rankdependent inequality index such as the Erreygers index since they impose that differences between subsequent SAH categories always represent the same health change (Erreygers and Van Ourti, 2011b). Instead, we use an interval regression estimation method proposed by Van Doorslaer and Jones (2003). It involves the estimation of an ordered probit model with thresholds not estimated but imposed from external data. This interval regression has the advantage of combining (i) the estimation of the relation between income and health in equation (2) with (ii) producing a predicted health score that we will use as the measure of health throughout our analyses and that has interval scale properties with a well-defined minimum and maximum value such that it is compatible with the Erreygers index:

$$
h_{i t}^{*}=a+f\left(y_{i t}\right)+x_{i t}{ }^{\prime} b+e_{i t}
$$

where $h_{i t}^{*}$ equals latent health, $e_{i t} \sim N\left(0, \sigma^{2}\right)$, and $a, b, f()$ are the empirical counterparts of $\alpha, \beta$ and $\phi()$ in equation (2). We impose thresholds obtained from the cumulative distribution of the Chinese visual analogue scale (VAS) in the World Health Organization's Multi-Country Survey Study on Health and Responsiveness (Üstün et al., 2003). A visual analogue scale allows respondents to rate their general health level along a continuous line. The VAS thresholds are obtained by calculating the cumulative frequency of VAS for each SAH category assuming a stable mapping of SAH into VAS (Van Doorslaer and Jones, (2003). The resulting thresholds are 0.91 (excellent/good), 0.80 (good/fair) and 0.50 (fair/poor); and the minimum and maximum VAS scores are 0 (minimum health) and 1 (maximum health). These thresholds allow us to interpret the predictions from the interval regression as VAS scores. They also show that the assumption of similar health differences between subsequent SAH categories - which would be imposed when using the ordered SAH responses - is unrealistic.

Household income is another crucial variable in this study. The CHNS collects detailed information on various income sources of the household, including income from wages, agriculture, own business and public/private transfers. Household income has been expressed in 2006 Yuan prices ( $¥ 100=€ 9.83$ ) using consumer price indices specific to each wave, province and county; an equivalence scale is used to allow for differences in household size by dividing household income by the square root of household size (Van de Poel et al., 2012). We use a flexible parameterization of the income effect since it is crucial for our decomposition approach to allow for heterogeneity in income effects across poor and rich individuals. We use a polynomial transformation of income as it is differentiable across the entire income range, and let the data determine the order of the polynomial by selecting the most parsimonious polynomial that does not statistically differ from a fifth order polynomial (at a 1 percent significance level).

The other variables $x_{i t}$ consist of a set of age-sex dummies, and a set of regional dummies. Sufficiently wide age ranges were adopted $(10-29,30-49,50-69$ and $70+)$ to ensure that all sex-age categories contain sufficient observations in each period over the 15 year study period. We also account for regional differences by including information on the region of residence. Following Bramall (2009) and Tafreschi (2011), we have divided the CHNS into four regions, defined by coastal/inland province and urban/rural areas reflecting that urban regions, and especially those in coastal provinces, have experienced the strongest economic development in China.

\footnotetext{
${ }^{7}$ If respondents systematically report different levels of SAH for similar objective health states, SAH might be prone to response heterogeneity (Bago d'Uva et al., 2008). While this will affect the level of IRHI, this is less important for the evolution of IRHI since reporting heterogeneity is most likely largely constant over time in a panel. The information in the CHNS does not allow to analyze this in more detail.
} 
We only include demographic and regional non-income variables in equation (5) since we want to provide evidence on the total association between changes in the distribution of income and the evolution of IRHI. We have not included variables that are potentially endogenous and related to the mechanisms underlying this association (such as education, labor force behavior, lifestyles, health insurance) as it would affect the estimate of the magnitude of this association. Hence, we only include variables that are exogenous to the association between income and health. This obviously holds for the standardizing variables age and sex, but in our context also for region since the CHNS does not record migration. For the same reason, we have refrained from using time fixed effects since these could pick up part of the income trend over the 15 year study period. ${ }^{8}$ This leaves us with a version of equation (5) in which the non-linear income function features as the sole potentially endogenous variable. We have deliberately not addressed its potential endogeneity since we are interested in documenting the association between changes in the distribution of income and the evolution of IRHI in China. Turning to the underlying mechanisms is only sensible after the magnitude of this association has been established, and after the relative importance of "income growth", "mean-preserving income changes", and "income mobility" has been understood.

We estimate equation (5) on all CHNS waves using a pooled interval regression model, and allow for clustering at the community level (which is the primary sampling unit in the CHNS and therefore leads to conservative statistical inference). It is not feasible to implement an individual fixed effects specification and estimates obtained from a random effects model were very similar to those of the pooled model. Since the random effects model imposes stronger exogeneity assumptions, we prefer the pooled model.

Remember that we highlighted three simplifying assumptions underlying equation (2) - and thus also equation (5). Here, we provide some justification. First, ruling out interactions between the non-linear income function, and age/sex/region is reasonable since alternative versions of the model in equation (5) show that most of the interactions are individually insignificant. ${ }^{9}$ Our second assumption was to fix the coefficients in equation (5) over time. We have checked its validity by adding interactions between time and the non-linear income function, and found almost none of the individual interactions to be statistically significant. ${ }^{10}$ Finally, we have ignored dynamics in the specification of equation (5) since the period between the various CHNS waves differs from wave to wave. ${ }^{11}$

\footnotetext{
${ }^{8}$ Adding time and cohort effects to equation (5), did not alter our conclusions reached in this paper.

${ }^{9}$ We also derived the counterpart of equation (4) that allows for these interactions. This shows that the subdivision in "income growth", "other mean-preserving changes", "income mobility" and "other variables" will change when the magnitude of the age/sex/region effect is strongly affected by the inclusion of these interactions in equation (5) for which we found no evidence in the CHNS data.

${ }^{10}$ A second sensitivity test consisted of estimating equation (5) in a pair-wise manner. In our main analysis in section 5, we estimate equation (5) on all CHNS waves and use the estimates as an input for each pair-wise decomposition of the change in IRHI between period $t$ and the first period (using equation (4)). A straightforward way to relax the assumption of fixed coefficients is to re-estimate equation (5) for each pair-wise decomposition between period $t$ and the first period; and to check whether this affects the results of our decomposition. We found hardly any differences between both approaches, except for the change in IRHI between 2004 and 1991 where we found larger, but still small differences. We take away from this sensitivity test that the assumption of fixed betas is reasonable in the CHNS data.

${ }^{11}$ Nevertheless, we have also estimated a version of equation (5) that includes a lagged dependent variable (ignoring the fact that the time lags are not constant across waves) and used the resulting estimates as an input for the decomposition. The results confirmed our findings in section 5 .
} 


\subsection{Selection of our sample, attrition, descriptives and statistical inference}

We use all waves of the CHNS that were available at the time of the analysis (1991, 1993, $1997,2000,2004,2006)$, except for the first wave (1989) which does not include the SAH question. $^{12}$

[Table 1]

Table 1 gives an overview of our sample selection criteria. Since our decomposition follows a cohort, we consider only those individuals that were present in 1991 and follow these individuals until 2006 (note that some individuals drop out in a particular year, and reappear in a later wave). We exclude the province of Heilongjiang since it did not participate in the the first 1991 wave of our cohort (see row 'Did not participate' in table 1). The province of Liaoning is included, but did not participate in the 1997 wave (see row 'Did not participate', column 1997 in table 1). This will affect our decomposition of the evolution of IRHI between 1991 and 1997, but not the decomposition for any of the other waves. We also delete all respondents under the age of 10 because the CHNS does not report the SAH question for these children in waves 1997, 2000 and 2004. We further drop all CHNS participants that did not report to either the SAH, date of birth, or income questions. In addition, we remove the two percent highest incomes from each wave ${ }^{13}$ and observations with negative incomes in $1991^{14}$ (see rows 'Household income...").

During the 15 years of follow-up, $61.2 \%$ of the initial cohort drops out for a variety of reasons such as mortality, moving (out) of the household or refusal to participate in later waves (see table 1). We correct for the impact of non-random dropout by applying inverse probability weights (IPW) to equations (4) and (5) (Jones et al., 2006). ${ }^{15}$ We provide further details in Appendix 1.

\section{[Table 2]}

Table 2 shows descriptive statistics for our CHNS cohort, both uncorrected and corrected for sample attrition (see below). We observe that health deteriorates with the ageing of our cohort. Average equivalent income more than doubled (in real terms) and this increase was not equally distributed: the Gini index for our cohort grew from 0.330 in 1991 to 0.445 in 2006. Most of the respondents in our initial cohort live in the inland rural areas (45.7\%), the cohort shares living in the inland urban and coastal rural areas are approximately equal, while the fewest respondents lived in the coastal urban areas (9.8\%).

\footnotetext{
${ }^{12}$ The 2009 wave was not available at the time of the analysis, but - more importantly - does not include the SAH question.

${ }^{13}$ With the two percent highest incomes included, the marginal effect of income turned negative at very high income levels, presumably due to the bounded nature of health in combination with the flexible, but parameterized polynomial transformation of income. The exclusion of the two percent highest incomes is of little practical importance since the decomposition results obtained from the total sample, including the two percent highest incomes, confirm the results reported in this paper.

${ }^{14}$ Negative incomes reflect negative returns of raising livestock, business, farming, gardening and fishing. They are problematic for our decomposition since individuals reporting negative incomes in 1991, will see their incomes decline in the hypothetical scenario of equi-proportional income growth. This seems an unwanted assumption and therefore we exclude all households with incomes smaller or equal to zero Yuan in 1991. Households that report positive incomes in 1991, but negative incomes in later waves are not excluded.

15 Petrie et al. (2011) have shown that IPW corrections for mortality lead to an overestimation of the remaining level of health in the cohort, but this concern is of limited relevance for our analysis since attrition in the CHNS is mainly driven by other causes than mortality (less than $8 \%$ of the 1991 cohort have died by 2006, compared to an overall attrition rate of $61.2 \%$ ). Moreover, application of our decomposition approach to (i) the cohort excluding all individuals that died during the study period, (ii) the balanced and (iii) unbalanced cohorts confirmed the decomposition results reported in this paper.
} 
Finally, we allow in our statistical inference for clustering at the level of the primary sampling units (i.e. communities) and use robust standard errors. This is straightforward for equation (5), and for the wave-specific Erreygers indices (O'Donnell et al., 2008), but more difficult for the other elements of our decomposition in equation (4) since (i) two consecutive waves of a panel are not independent and because (ii) the combined sampling variability in the estimates of the IPWs, equation (5), and proportional income growth $\left(Y_{t} / Y_{1}\right)$ should be accounted for. To this end, we bootstrap the entire procedure, i.e. from IPWs to the 4 terms of our decomposition. We draw 2000 bootstrap samples of communities (Mills and Zandvakili, 1997) and address the dependence between panel waves by drawing bootstrap samples of the communities in the first wave only (and use these same communities for all later waves).

\section{RESULTS}

Table 2 showed that the 1991 cohort of the CHNS experienced a dramatic increase in average incomes and income inequality over the period 1991-2006. In this section, we link these changes to the evolution of IRHI.

\subsection{Evolution of IRHI and changes in the income distribution in China}

The trends in table 2 are illustrated in greater detail in panel $b$ of figure 1 showing that, on top of proportional income growth, the spread of incomes has increased between 1991 and 2006. Panel a of the same figure shows that IRHI more than doubled from 0.013 in 1991 to 0.041 in 2006, and this trend has favored the rich throughout as indicated by the positive values of the Erreygers indices. Our finding of a large increase in IRHI between 1991 and 2006 is a first and important finding of this paper, and the starting point for the subsequent analyses.

\section{[Figure 1]}

\subsection{The relation between health, income and non-income variables in China}

An essential ingredient to understand these rising IRHI is the relationship between health and income conditional on the non-income variables. The interval regression estimates of equation (5) reported in column (1) of table 3 show that demographics play a major role: (VAS-scaled) SAH deteriorates monotonically with age and is higher for males than females. We also find that those living in coastal and rural areas report better health, which is consistent with Van de Poel et al. (2012) who found urbanization in China to raise the probability of reporting poor health. Finally, the relationship between income and health is best described by a third degree income polynomial, giving rise to the income profile in figure 2: health increases with income at a decreasing rate, but for very high incomes ( inflection point at 22,048 Yuan), the marginal effect of additional income starts rising again. The cumulative income distributions for 1991 and 2006 in figure 2 confirm that this only occurs for a minor share of our cohort: in 1991, no individuals had an income level above the point of inflection, whereas in 2006 , this was about $13 \%$ percent.

\section{[Table 3]}

While this cannot be inferred from figure 2, the underlying estimates in table 3 indicate that proportional income changes have overall similar health effects among those with lower, middle and higher incomes (see also section 3.2). It follows that according to our decomposition framework, proportional income growth will - ceteris paribus - be associated with constant IRHI. This is a second, and perhaps more surprising, finding of our paper: 
despite the enormous improvement of average incomes in China over the last few decades, these proportional income gains do not help us understand the rising IRHI in China.

[figure 2]

\subsection{Decomposition of evolution of IRHI in China}

Figure 3 and table A. 2 in the appendix show estimates of the 4 terms of our decomposition: (i) income growth; (ii) other mean-preserving changes in the income distribution; (iii) differences in income mobility across non-income variables; and (iv) differences in the evolution of non-income variables across the initial income distribution. We discuss each of these terms, including statistical inference, in detail.

First, proportional income growth only shows a minor (and statistically insignificant) association with IRHI. This means that income growth in China is not related to rising IRHI, as was already anticipated by the earlier finding that proportional income changes have an overall uniform health effect across the income distribution.

Second, compared to proportional income growth, 'other mean-preserving changes in the income distribution' are more important for IRHI. Given that proportional income increases are associated to a similar health gains across the income spectrum, this must be due to the pro-rich changes in the Chinese income distribution that we reported in figure 1 and table 2 . Hence, our results confirm that the rise in Chinese income inequality is associated with increasing IRHI, but it also confirms that the other elements of our decomposition must be more important: in none of the waves the 'mean-preserving changes' account for more than 25 percent of the change in IRHI (and in several waves far less). It is also worth noting that the 'direct' effects of changes in the income distribution (i.e. term (1) and term (2)) only account for around 30 percent of the rise in IRHI.

[Figure 3]

Third, differences in the evolution of the non-income variables (term 4) show a small, but statistically significant, negative effect on IRHI in figure 3 . This effect is entirely driven by the evolution of age since sex and region are time-invariant in the CHNS. In other words, this term isolates the impact of ageing on the change of IRHI over time. We find that ageing contributes to IRHI (i.e. IRHI would have increased slightly more without ageing) due to the initially rich experiencing larger health declines due to ageing compared to the initially poor. This is confirmed by the right panel of figure 4 which shows the separate contributions of the different age-sex groups. ${ }^{16}$

It is clear by now that most of the change in IRHI must be related to differential income mobility across the non-income variables (term 3 in equation (4)). Differential income mobility by age, sex and region accounts for around 70 to $90 \%$ of the total evolution in IRHI (see figure 3). This means that individuals that are sliding downward in the income distribution are less healthy compared to the reference group of young (and healthy)

\footnotetext{
${ }^{16}$ For example, we find a relatively large negative effect for females in age group 50-69. As an example, we explain how this negative effect should be interpreted; a similar reasoning applies to the other age-sex groups. First, the female 50-69 age group has a large negative coefficient $\beta^{k}$ in the interval regression (see also column 1 in table 3). Consequently, for a female to contribute negatively to the 50-69 age group, it must be that $\left(x_{i t}^{k}-x_{i 1}^{k}\right) z_{i 1}>0$. This will happen when she enters the 50-69 group and is relatively rich, i.e. $\left(x_{i t}^{k}-x_{i 1}^{k}\right)>0$ and $z_{i 1}>0$, or when she leaves this age group and is rather poor, i.e. $\left(x_{i t}^{k}-x_{i 1}^{k}\right)<0$ and $z_{i 1}<0$. Second, females not changing age groups, do not contribute to term 4.
} 
females living in inland-rural areas. The left panel of figure 4 and table A.2 illustrate that regional differences in income mobility have a small, and insignificant effect (reference category: inland-rural), and they are clearly dominated by the differential income mobility across sex-age categories (youngest females are the reference). There is no statistically significant difference between males younger than 50 and females younger than 30 (the reference category), and for females in the age group 30-50, we observe a negative insignificant effect. By far the strongest effects are observed for males and females above 50 years who were downwardly income mobile and less healthy than the younger age groups. The effects for $50+$ females are in most cases also substantially larger and more significant than for $50+$ males.

\section{[Figure 4]}

This begs the question why the effect for elderly females is that much larger than for elderly males. Closer inspection of term 3 in equation (4) reveals that the effect for a given age-sex category is driven by three components: (i) the health of this age-sex category (compared to the reference group), (ii) the share of people in this category, and/or (iii) whether this group has been upwardly or downwardly income mobile. ${ }^{17}$ In other words, elderly females can show a larger effect than elderly males for three reasons: because they report lower health, because there are more elderly women in our cohort in any given wave, or because elderly women are more downwardly mobile than elderly males. Table 3 presents some evidence on the relative importance of these three elements for all age-sex (and regional) categories. It shows that the diverging patterns between elderly women and men in figure 4 are mainly related to differences in income mobility (see columns 7-11), and less to the lower health level of females (column 1) or their relative group size (columns 2-6), although these clearly also matter.

We thus conclude that differential income mobility across age-sex groups is the single most essential element to understand the evolution of IRHI in China. Young (and healthier) individuals have been much more upwardly mobile compared to those above 50 , and this age difference is more pronounced among females than males, in particular among those older than 70. While the inferior health of older women and their increasing group size over time have also contributed to this phenomenon, downward income mobility of elderly women (compared to young women) is much more important. We have also established that rising income inequalities account for less than a quarter of the change in IRHI and that ageing in China even slightly reduces IRHI. Perhaps the most surprising result is the lack of any association between income growth and rising IRHI in China.

\subsection{Further unraveling the downward income mobility of elderly (females): an exploration}

Despite its importance for understanding the evolution of IRHI in China, table 3 does not explain why the $50+$ (and in particular women in the 70+ group) have experienced a greater downward shift in their income positions since 1991 compared to younger and healthier generations. In this section we explore a potential explanation.

A first useful observation is that our analysis has been based on equivalent incomes (see also section 4.1). Hence, the downward shifts can be driven by changes in either the numerator

\footnotetext{
${ }^{17}$ Since we use IPWs, an additional source of variation emerges, i.e. the difference between the IPW-weighted age-sex (and regional) composition and the one that would have prevailed without attrition. Only in the unlikely case when the IPWs predict attrition perfectly, this source of variation will vanish. We do indeed find that the IPWs are not perfect, but its effect on term 3 of our decomposition is negligible compared to the other three drivers, and if anything, reduces - rather than raises - the effect of the 70+. In order not to complicate the results too much, we do not report this additional source of bias. More information can be obtained from the authors.
} 
(household income) or the denominator (household size), or both. It turns out that the diverging pattern for the elderly compared to younger age cohorts - and for elderly women compared to men - is not driven by changes in household size, but by changes in household incomes. ${ }^{18}$ Therefore, explanations based on changes in household composition only cannot explain differential income mobility between the young/healthy and the old/unhealthy (and amongst the elderly) in China.

Instead, an explanation that focuses on changes in household incomes squares with evidence on replacement incomes and income support for the elderly in China. Elderly in rural areas - especially those above 70 - typically do not receive any pension benefits and still largely rely on family-based self-insurance mechanisms. These insurance mechanisms have become more uncertain due to a combination of China's demographic transition leading to smaller family sizes, less co-residence and fewer extended families (Zhong, $2011)^{19}$ as well as to migration of (mainly young) adults from rural to urban areas (Giles et al., 2010). Similarly, urban dwellers - in spite of having more favorable pension arrangements than rural citizens - have been confronted with pension arrears, due to bankruptcies of state-owned enterprises and due to limited compliance with recent pay-as-you-go local pension initiatives. Traditional family-based insurance mechanisms have only partially protected elderly urban residents from these pension arrears (Cai et al., 2006). Nevertheless, urban residents have 'on average' continued to receive pension benefits that are largely unavailable to rural citizens (Feldstein, 1999; Yang, 1999). Giles et al. (2010) show that less than 5 percent of elderly rural residents relied on pension incomes in 2005 whereas this share was 45 percent in urban areas. Moreover, and in line with our findings in table 3 , these authors report that pension incomes are more concentrated among elderly males in both rural and urban areas, while females rely more on family-based income support which, according to Meng et al. (2007), is explained by higher former labor market participation of males. Finally, Knight et al. (2004) show that rising income inequality in Chinese coastal cities was mainly related to changes in wage incomes whereas pension incomes accounted for the largest share of rising income inequalities in inland urban areas.

Two lessons emerge from this brief review for this paper. First, it confirms that our findings of differential income mobility between the young and old (and between elderly males and females) are in line with the evidence to date. Secondly, and more importantly, it points to a potentially crucial difference between rural and urban areas and between inland-urban and coastal-urban areas. All of these studies suggest that differential income mobility should play a more important role in rural and inland-urban areas than in coastal urban areas. Hence, we repeated our decomposition of IRHI in section 5.3 (and the interval regression models in section 5.2) separately for the four regions defined by inland/coastal and urban/rural. While this leaves us with more than 1000 observations for each of the rural regions, the number of observations in the urban regions becomes fairly small in the last wave of the CHNS, i.e. respectively 294 and 802 respondents in the urban-coastal and urbaninland areas.

[Figure 5]

\footnotetext{
${ }^{18}$ For example, the average female (male) in the 10-29 age range in 2006 had seen her (his) household income rise with a ratio of 3.04 (3.09) while this ratio was only 1.25 (1.83) for the average female (male) in the oldest age group. Similar ratios for household size amounted to 1.07 and 0.83 for females and 1.09 and 0.75 for men.

${ }^{19}$ Zhong (2011) also finds that population ageing accounts for a substantial share of rising income inequality in rural China, but not in urban China.
} 
Figure 5 shows the evolution of IRHI for the four different regions. Inequalities were highest in the two inland and coastal-rural areas, and the magnitude of IRHI in these regions was comparable to that of the entire sample (in figure 1). The urban areas in the coastal provinces followed a different pattern and IRHI were smaller (and insignificant) in all periods. For each region, we present the decomposition of the evolution of IRHI between 1991 and 2006 in Figure 6. These decompositions show a similar grouping for the two inland and coastal-rural areas versus the coastal urban area. The decomposition of the former three areas is very similar to that of the entire sample (but significance levels are lower) and is also here dominated by differences in income mobility across age groups. In contrast, income growth and other mean-preserving changes in the income distribution are more substantive in the coastal urban areas, while differential income mobility across age-sex categories is negligible. However, none of the terms of the decomposition for the urban-coastal region is still significant - probably as a result of small sample size - and we thus have to be careful in interpreting these as contributions to the evolution of IRHI.

[Figure 6]

Our findings per region thus suggest that while overall in China IRHI are to a large extent driven by differences in income mobility between the young and the elderly, and between sexes amongst the elderly, regional differences in income protection (via family based insurance mechanisms or more formal pension systems) appear crucial to understand this phenomenon. It also means that the younger cohorts have gained most from the economic prosperity in recent decades in China, except for the coastal urban areas where all age groups seem to have benefited equally.

\section{Conclusions}

The rapid economic growth in China in recent decades has been accompanied by larger inequalities in society, not only with respect to income, but also with respect to health. This begs the question how the dramatic changes in both the level and distribution of Chinese household incomes over the last few decades have been related to the extent to which also health - as self-reported - is distributed unequally by income. We believe we make the following contributions. First, we propose a new cohort-decomposition of the changes in IRHI into four components: (i) the growth of mean income, (ii) mean-preserving changes in the distribution of incomes, (iii) the income mobility across other important variables like age and region, and (iv) changes in initial income rank. It differs from earlier approaches in two respects: (a) it extends and simplifies earlier decomposition approaches by replacing the standard concentration index by the Erreygers index which recognizes that health - unlike income - has a finite maximum; (b) it highlights the importance of income mobility when it varies across important determinants of health like age and region. Secondly, we empirically implement the approach using data from the CHNS, one of the longest running panel studies, by estimating health as a polynomial function of income, controlling for age, gender and region. While this does not allow for causal inference, the decomposition analysis does reveal which factors are important - and which are not - for understanding the evolution of health disparities by income in China.

Our findings are as follows. We find that IRHI rose quite substantially in this cohort: between 1991 and 2006 its degree has more than tripled. No other study had revealed this rise before, and in the absence of ageing of our cohort the rise would have been larger. Also new is that this substantive rise turns out to be largely unrelated to the double digit average income growth rates and only weakly related to the overall growth in income inequality. Instead, what emerges is that most of the increase in IRHI relates to the very different income 
mobility by age and gender. Especially women over 50 in the cohort have experienced much more adverse trends than other groups in their income position (and their health) and this explains more than half of the growth in IRHI. This strongly suggests that elderly women were left behind in the rapid economic developments occurring in China and that low or absent replacement incomes for sick and old women are a key factor here. While we have not directly tested this hypothesis, it conforms to the literature on retirement incomes. This confirms that, especially in rural areas, pension entitlements are largely lacking for the majority of the population. Reliance on traditional, family-based self-insurance has also declined because of demographic transitions like smaller family sizes and migration. Urban and male residents have generally enjoyed more favorable pension arrangements because of their greater participation in the formal labor market. This explanation also squares with the regional differences in our findings: income mobility did not contribute as much to IRHI changes in the coastal urban areas as in the other regions. This suggests that income protection and pension arrangements, also for older women, in this region are better than in other parts of China.

Our study is thus a first step in understanding the evolution of IRHI in China and its relation with changes in the income distribution. Our findings strongly suggest that the following issues deserve attention in further research. First, how are age profiles of income related to age profiles of health in China, and in particular why are low replacement incomes associated with low health? Our results suggest that this is a structural relationship and Giles et al. (2010) emphasize that many elderly without any replacement income are still working. It is most likely that this has consequences for their health. Secondly, it appears relevant to investigate further the different experiences in urban coastal areas with other regions to find out which differences in institutions versus demographics matter. Finally, it would be of interest to examine whether differential income mobility among the elderly is related to changes in household composition due to mortality or migration of income earning members.

\section{Appendix 1: implementation of inverse probability weights}

The IPW-methodology consists of two distinct steps. First, for all respondents in the first wave, one estimates the probability of still being present in wave t. Second, the inverse of the resulting predicted probabilities are used as probability weights in wave t, i.e. as an IPW, in all analyses.

[table A.1]

For each wave, we estimate a separate probit, and include the following wave 1 regressors: (a) a polynomial of equivalent income, (b) dummies for the separate SAH categories, and (c) sex-age dummies and regional dummies. The results in table A.1 show that the middle aged (30-70) are most likely to stay in the cohort, and that young females are most likely to leave the cohort (in later waves elderly males are least likely to stay probably due to mortality). We also observe that those living in rural $\operatorname{areas}^{20}$ and those in good health are most likely to stay in the cohort. The effect of income is non-linear in most waves and indicates that those with higher incomes (except for those with very low and very high incomes) are more likely to drop out of the cohort. Most importantly, we found that the interactions between the income polynomial and the set of SAH dummies were jointly insignificant and therefore removed these from the probit models. This indicates that selective health-income dropout is unlikely to be a serious problem in our data.

\footnotetext{
${ }^{20}$ Note that the coefficients for the coastal regions are much more negative in 1997 since the province Liaoning did not participate in the CHNS in that wave.
} 
While the IPWs should in principle be used in all analyses, we only use them for the estimation of equation (5), for the weighted income $z_{i t}{ }^{\prime 21}{ }^{21}$ (Lerman and Yitzhaki, 1989), for calculating average income in each wave $Y_{t}$ which is needed to calculate $y_{i t}^{p g}$, and for the left-hand side Erreygers indices in equation (4). ${ }^{22}$ The IPW's are partially needed for terms (2) and (3) and not for terms (1) and (4) of equation (4). The latter two terms can be calculated without the IPWs since we know what would have been the age, sex, and region of individuals that have dropped out of the cohort. Similarly, we can calculate the incomes in the 'proportional income growth' scenario since equivalent income in the first period is known.

\section{Acknowledgment}

This research uses data from the China Health and Nutrition Survey (CHNS). We thank the National Institute of Nutrition and Food Safety, China Center for Disease Control and Prevention, Carolina Population Center, the University of North Carolina at Chapel Hill, the $\mathrm{NIH}$ (R01-HD30880, DK056350, and R01-HD38700) and the Fogarty International Center, NIH for financial support for the CHNS data collection and analysis files from 1989 to 2006 . We also acknowledge support from the National Institute on Ageing, under grant R01AG037398, and the NETSPAR funded project "Income, health and work across the life cycle" and the FP7 EU funded project on Health equity and financial protection (HEFPA). We have benefited from the comments and suggestions of Owen O'Donnell, Raül Santaeulàlia-Llopis, Darjusch Tafreschi and participants of seminars at Erasmus University Rotterdam, the 2011 iHEA Conference in Toronto and the 2012 Health, Development and Inequality conference in Darmstadt. We also thank Raman Ahmed for research assistance and Ellen Van de Poel for help with the CHNS data. The usual caveats apply and all remaining errors are our responsibility.

\section{References}

Allanson, P.F., Gerdtham, U.-G., Petrie, D., 2010. Longitudinal analysis of income-related health inequality. J. Health Econ. 29, 78-86.

Bago d'Uva, T., van Doorslaer, E., Lindeboom, M., O'Donnell, O., 2008. Does reporting heterogeneity bias the measurement of health disparities? Health Econ. 17, 351375.

Benjamin, D., Brandt, L., Giles, J., Wang, S., 2008. China's great economic transformation, in: Brandt, L., Rawski, T.G. (Eds.), China's Great Economic Transformation. Cambridge University Press, pp. 729-775.

Bramall, C., 2009. Chinese Economic Development. Routledge, London, New York.

Brun, J.F., Combes, J.-L.C., Renard, M.-F., 2002. Are there spillover effects between coastal and noncoastal regions in China? China Econ. Rev. 13, 161-169.

Cai, F., Giles, J., Meng, X., 2006. How well do children insure parents against low retirement income? An analysis using survey data from urban China. J. Public Econ. 90, 22292255.

Carolina Population Center, 2010. China Health and Nutrition Survey [WWW Document]. http://www.cpc.unc.edu/projects/china/.

Chang, G.H., 2002. The cause and cure of China's widening income disparity. China Econ. Rev. $13,335-340$.

$$
\begin{aligned}
& { }^{21} z_{j t}^{\mid P W}=0.5\left(\sum_{l=1}^{n_{t}} I P W_{l t}\right)-\left(\sum_{l=1}^{j-1} I P W_{l t}+0.5 I P W_{j t}\right) \\
& { }^{22} C_{E}^{P W}\left(h_{t} \mid y\right)=\left[8 /\left(\sum_{j=1}^{n_{t}} I P W_{j t}\right)^{2}\right] \sum_{j=1}^{n_{t}}\left(I P W_{j t} z_{j t} h_{j t}\right)
\end{aligned}
$$


Chen, J., Fleisher, B.M., 1996. Regional income inequality and economic growth in China. J. Compar. Econ. 22, 141-164.

Chen, Z., Eastwood, D.B., Yen, S.T., 2007. A decade's story of childhood malnutrition inequality in China: Where you live does matter. China Econ. Rev. 18, 139-154.

Chen, Z., Meltzer, D., 2008. Beefing up with the Chans: Evidence for the effects of relative income and income inequality on health from the China Health and Nutrition Survey. Soc. Sci. Med. 66, 2206-2217.

Contoyannis, P., Forster, M., 1999. The distribution of health and income: a theoretical framework. J. Health Econ. 18, 603-620.

Erreygers, G., 2009a. Correcting the Concentration Index. J. Health Econ. 28, 504-515.

Erreygers, G., 2009b. Correcting the Concentration Index: A reply to Wagstaff. J. Health Econ. 28, 521-524.

Erreygers, G., Van Ourti, T., 2011a. Putting the cart before the horse. A comment on Wagstaff on inequality measurement in the presence of binary variables. Health Econ. 20, 1161-1165.

Erreygers, G., Van Ourti, T., 2011b. Measuring socioeconomic inequality in health, health care and health financing by means of rank-dependent indices: A recipe for good practice. J. Health Econ. 30, 685-694.

Feldstein, M., 1999. Social security pension reform in China. China Econ. Rev. 10, 99-107.

Feng, X.L., Zhu, J., Zhang, L., Song, L., Hipgrave, D.B., Guo, S., Ronsmans, C., Guo, Y., Yang, Q., 2010. Socio-economic disparities in maternal mortality in China between 1996 and 2006. Br. J. Obstet. Gynaecol. 117, 1527-1536.

Fortin, N., Lemieux, T., Firpo, S., 2011. Decomposition Methods in Economics, in: Orley, A., David, C. (Eds.), Handbook of Labor Economics, volume 4, part A. Elsevier, Amsterdam, pp. 1-102.

Giles, J., Wang, D., Zhao, C., 2010. Can China's Rural Elderly Count on Support from Adult Children? Implications of Rural-to-Urban Migration. J. Popul. 3, 183-204.

Gustafsson, B., Shi, L., Sicular, T., 2008. Inequality and Public Policy in China. Cambridge University Press.

Gustafsson, B., Shi, L., Zhong, W., 2006. The distribution of wealth in urban China and in China as a whole in 1995. Rev. Income Wealth 52, 173-188.

Hougaard, J.L., Østerdal, L.P., Yu, Y., 2011. The Chinese healthcare system: structure, problems and challenges. Appl. Health. Econ. Health Policy 9, 1-13.

Jones, A.M., Koolman, X., Rice, N., 2006. Health-related non-response in the British Household Panel Survey and European Community Household Panel: using inverseprobability-weighted estimators in non-linear models. J. Roy. Statistical Society 169 , 543-569.

Jones, A.M., Nicolás, A.L., 2004. Measurement and explanation of socioeconomic inequality in health with longitudinal data. Health Econ. 13, 1015-1030.

Kanbur, R., Zhang, X., 2005. Fifty Years of Regional Inequality in China: a Journey Through Central Planning, Reform, and Openness. Rev. Devel. Econ. 9, 87-106.

Keidel, A.I., 2009. Chinese regional inequalities in income and well-being. Rev. Income Wealth 55, 538-561.

Khor, N., Pencavel, J.H., 2010. Poverty, Inequality, and Inclusive Growth in Asia: Measurement, Policy Issues, and Country Studies, in: Zhuang, J. (Ed.), Evolution of Income Mobility in the People's Republic of China: 1991-2002, volume 204. pp. 387408.

Knight, J., Shi, L., Renwei, Z., 2004. Divergent Means and Convergent Inequality of Incomes among the Provinces and Cities of Urban China (Working Paper No. UNU-WIDER Research Paper RP2004/52). World Institute for Development Economic Research (UNU-WIDER). 
Lambert, P.J., 2001. The distribution and redistribution of income. Manchester University Press.

Lambert, P.J., Zheng, B., 2011. On the consistent measurement of attainment and shortfall inequality. J. Health Econ. 30, 214-219.

Lerman, R.I., Yitzhaki, S., 1989. Improving the accuracy of estimates of Gini coefficients. J. Econometrics 42, 43-47.

Lin, T., Zhuang, J., Yarcia, D., Lin, F., 2008. Income Inequality in the People's Republic of China and Its Decomposition: 1990-2004. Asian Dev. Rev. 25, 119-136.

Liu, G.G., Dow, W.H., Fu, A.Z., Akin, J., Lance, P., 2008. Income productivity in China: On the role of health. J. Health Econ. 27, 27-44.

Meng, X., Gregory, R., Wan, G., 2007. Urban Poverty in China and its contributing factors, 1986-2000. Rev. Income Wealth 53, 167-189.

Mills, J.A., Zandvakili, S., 1997. Statistical inference via bootstrapping for measures of inequality. J. Appl. Econometrics 12, 133-150.

O'Donnell, O., van Doorslaer, E., Wagstaff, A., Lindelow, M., 2008. Analyzing Health Equity Using Household Survey Data. The World Bank, Washington, DC.

Petrie, D.J., Allanson, P.F., Gerdtham, U.-G., 2011. Accounting for the dead in the longitudinal analysis of income-related health inequalities. J. Health Econ. 30, 11131123.

Shen, Y., Yao, Y., 2008. Does grassroots democracy reduce income inequality in China? J. Public Econ. 92, 2182-2198.

Shi, J., Liu, M., Zhang, Q., Lu, M., Quan, H., 2008. Male and Female Adult Population Health Status in China: A Cross-Sectional National Survey. BMC Public Health 8, 277.

Sicular, T., Ximing, Y., Gustafsson, B., Shi, L., 2007. The urban-rural income gap and inequality in China. Rev. Income Wealth 53, 93-126.

Sutherland, D., Yao, S., 2011. Income Inequality in China Over 30 Years of Reforms. Camb. J. Reg. Econ. Soc. 4, 91-105.

Tafreschi, D., 2011. The Income Body Weight Gradients in the Developing Economy of China. University of St. Gallen, School of Economics and Political Science.

Tang, S., Meng, Q., Chen, L., Bekedam, H., Evans, T., Whitehead, M., 2008. Tackling the challenges to health equity in China. Lancet 372, 1493-1501.

Üstün, T.B., Chatterji, S., Villanueva, M., Bendib, L., Çelik, C., Sadana, R., Valentine, N.B., Ortiz, J.P., Tandon, A., Salomon, J.A., Cao, Y., Xie, W.J., Özaltin, E., Mathers, C.D., Murray, C.J.L., 2003. WHO multi-country survey study on health and responsiveness, 20002001, in: Murray, C.J.L., Evans, D.B. (Eds.), Health Systems Performance Assessment: Debates, Methods and Empiricism. World Health Organization, Geneva., pp. 761796.

Van de Poel, E., O'Donnell, O., Van Doorslaer, E., 2012. Is there a health penalty of China's rapid urbanization? Health Econ. 21, 367-385.

van Doorslaer, E., Jones, A.M., 2003. Inequalities in self-reported health: validation of a new approach to measurement. J. Health Econ. 22,61-87.

Van Ourti, T., van Doorslaer, E., Koolman, X., 2009. The effect of income growth and inequality on health inequality: Theory and empirical evidence from the European Panel. J. Health Econ. 28, 525-539.

Wagstaff, A., 2009. Correcting the concentration index: A comment. J. Health Econ. 28, 516520.

Wagstaff, A., 2011a. The concentration index of a binary outcome revisited. Health Econ. 20, $1155-1160$.

Wagstaff, A., 2011b. Reply to Guido Erreygers and Tom Van Ourti's comment on "The concentration index of a binary outcome revisited". Health Econ. 20, 1166-1168. 
Wagstaff, A., Lindelow, M., Wang, S., Zhang, S., 2009a. Reforming China's Rural Health System. World Bank, Washington DC.

Wagstaff, A., Paci, P., van Doorslaer, E., 1991. On the measurement of inequalities in health. Soc. Sci. Med. 33, 545-557.

Wagstaff, A., van Doorslaer, E., 2000. Income Inequality and Health: What Does the Literature Tell Us? Annu. Rev, Public Health 21, 543-567.

Wagstaff, A., van Doorslaer, E., Watanabe, N., 2003. On decomposing the causes of health sector inequalities with an application to malnutrition inequalities in Vietnam. J. Econometrics 112, 207-223.

Wagstaff, A., Yip, W., Lindelow, M., Hsiao, W.C., 2009b. China's health system and its reform: a review of recent studies. Health Econ. 18, S7-S23.

Wang, X., Piesse, J., 2010. Inequality and the Urban-rural Divide in China: Effects of Regressive Taxation. China \& World Econ. 18, 36-55.

World Bank, 2005. PovCalNet [WWW Document]. http://iresearch.worldbank.org/PovcalNet.

Yang, D.T., 1999. Urban-Biased Policies and Rising Income Inequality in China. Amer. Econ. Rev. 89, 306-310.

Yip, W., 2010. Disparities in health care and health status: the rural-urban gap and beyond., in: Whyte, M.K. (Ed.), One Country, Two Societies: Rural-urban Inequality in Contemporary China. Harvard University Press, pp. 147-165.

Yu, Y., 2008. Comment on "Reform, Growth, and Inequality in China". Asian Econ. Policy Rev. 3, 161-162.

Zhang, X., Kanbur, R., 2005. Spatial inequality in education and health care in China. China Econ. Rev. 16, 189-204.

Zhong, H., 2011. The impact of population aging on income inequality in developing countries: Evidence from rural China. China Econ. Rev. 22, 98-107. 
Table 1: Reasons for dropout and exclusion from CHNS sample

\begin{tabular}{|c|c|c|c|c|c|c|}
\hline \multirow{2}{*}{ Exclusion criterion/reason for dropout } & \multicolumn{6}{|c|}{ wave } \\
\hline & 1991 & 1993 & 1997 & 2000 & 2004 & 2006 \\
\hline Initial number of observations ${ }^{\mathrm{a}}$ & 27,812 & 11,577 & 11,577 & 11,577 & 11,577 & 11,577 \\
\hline Died before interview & 0 & 102 & 366 & 569 & 789 & 898 \\
\hline Left household before interviewd & $1,113^{\mathrm{c}}$ & 741 & 0 & 0 & 0 & 0 \\
\hline Did not participate in interview (reason unknown) & 11,914 & 632 & 3,211 & 3,423 & 4,745 & 3,432 \\
\hline Younger than 10 years & 2,540 & 0 & 0 & 0 & 0 & 0 \\
\hline Unknown date of birth & 8 & 0 & 0 & 0 & 0 & 0 \\
\hline No household income & 20 & 19 & 67 & 128 & 61 & 125 \\
\hline Household income smaller or equal to zero ${ }^{\dagger}$ & 73 & 0 & 0 & 0 & 0 & 0 \\
\hline Household income among highest $2 \%$ & 252 & 158 & 146 & 147 & 113 & 114 \\
\hline No self reported health & 315 & 96 & 1,042 & 2,056 & 1,217 & 2,522 \\
\hline Total number of observations & $11,577^{b}$ & 9,829 & 6,745 & 5,254 & 4,652 & 4,486 \\
\hline
\end{tabular}

a. Based on unique number of individuals participating in any wave of the CHNS

b. The 11,577 respondents form our cohort at baseline

c. These respondents participated in 1989, but not in 1991

d. Only recorded in 1991 and 1993

e. Includes households that did not participate at all

f. Only applicable in 1991 
Table 2: Descriptives of CHNS 1991 cohort

\begin{tabular}{|c|c|c|c|c|c|c|c|}
\hline & Variable & 1991 & 1993 & 1997 & 2000 & 2004 & 2006 \\
\hline \multirow{12}{*}{ 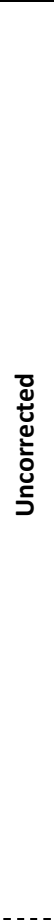 } & $\mathrm{N}$ & 11,577 & 9,829 & 6,745 & 5,254 & 4,652 & 4,486 \\
\hline & Average age & 35.7 & 37.7 & 42.2 & 47.2 & 51.6 & 53.4 \\
\hline & Region & & & & & & \\
\hline & Coastal rural & $24.0 \%$ & $25.2 \%$ & $19.9 \%$ & $25.6 \%$ & $25.5 \%$ & $25.5 \%$ \\
\hline & Inland urban & $20.5 \%$ & $19.2 \%$ & $21.3 \%$ & $19.7 \%$ & $18.7 \%$ & $17.9 \%$ \\
\hline & Inland rural & $45.7 \%$ & $46.5 \%$ & $54.0 \%$ & $46.6 \%$ & $49.6 \%$ & $50.1 \%$ \\
\hline & Average equivalent income $(¥, 2006)$ & $¥ 4,823$ & $¥ 5,354$ & $¥ 6,508$ & $¥ 7,756$ & $¥ 8,833$ & $¥ 10,270$ \\
\hline & Income distribution (gini) & 0.330 & 0.370 & 0.371 & 0.403 & 0.432 & 0.443 \\
\hline & Good & $61.7 \%$ & $63.6 \%$ & $60.9 \%$ & $47.9 \%$ & $42.6 \%$ & $44.2 \%$ \\
\hline & Fair & $21.1 \%$ & $20.1 \%$ & $23.4 \%$ & $33.2 \%$ & $37.8 \%$ & $38.0 \%$ \\
\hline & Poor & $3.7 \%$ & $3.8 \%$ & $4.5 \%$ & $7.1 \%$ & $9.1 \%$ & $9.2 \%$ \\
\hline & Average health & 0.812 & 0.809 & 0.800 & 0.792 & 0.780 & 0.777 \\
\hline \multirow{4}{*}{ 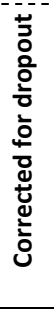 } & Percentage females & 0.508 & 0.508 & 0.512 & 0.51 & 0.514 & 0.51 \\
\hline & Average age & 35.7 & 37.5 & 41.4 & 45.2 & 49.8 & 51.8 \\
\hline & Region & & & & & & \\
\hline & Coastal urban & $9.8 \%$ & $9.9 \%$ & $10.7 \%$ & $10.7 \%$ & $12.2 \%$ & $11.4 \%$ \\
\hline
\end{tabular}




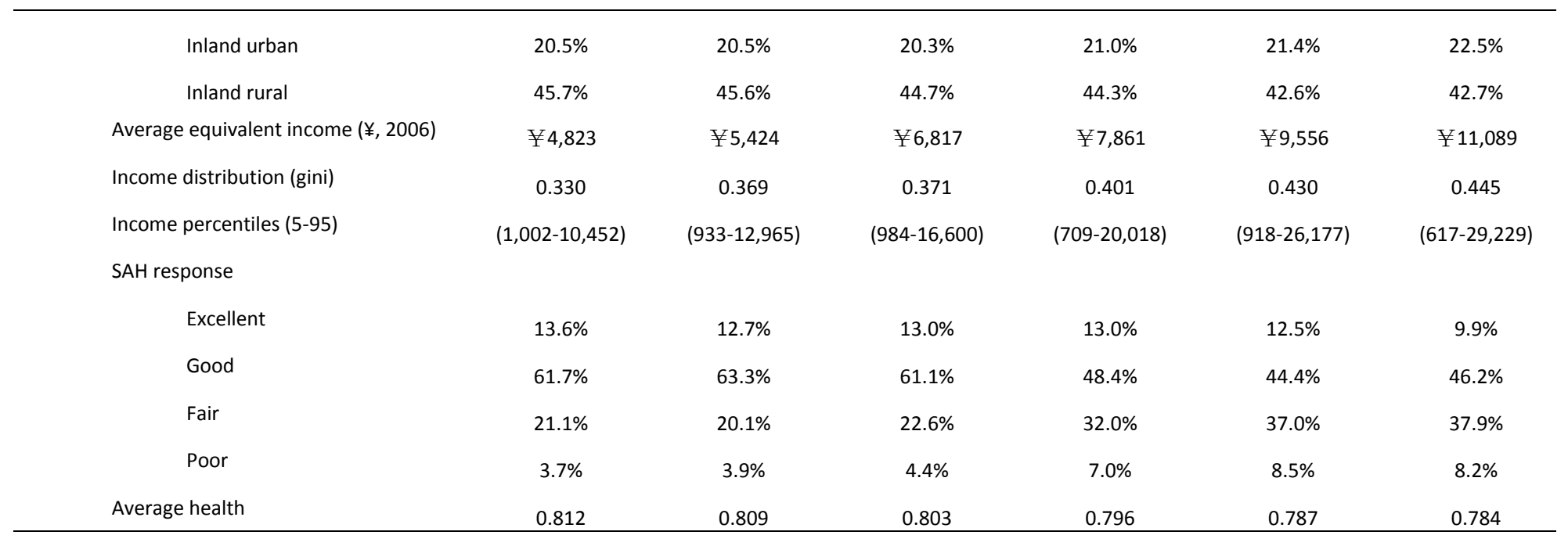


Table 3: Health Equation Estimates and Drivers of Differential Income Mobility

\begin{tabular}{|c|c|c|c|c|c|c|c|c|c|c|c|}
\hline \multirow{3}{*}{ Variable } & \multirow{3}{*}{$\begin{array}{c}\text { Interval } \\
\text { regression } \\
\text { coefficient }^{\mathrm{a}, \mathrm{b}}\end{array}$} & \multicolumn{5}{|c|}{ share of individuals in age-sex / region category $k$} & \multicolumn{5}{|c|}{ difference between average weights $z_{i t} \diamond$} \\
\hline & & 1993 & 1997 & 2000 & 2004 & 2006 & 1993 & 1997 & 2000 & 2004 & 2006 \\
\hline & & (2) & (3) & (4) & (5) & (6) & (7) & (8) & (9) & (10) & (11) \\
\hline \multicolumn{12}{|l|}{ Females } \\
\hline $10 \_29$ & Reference & 0.194 & 0.147 & 0.069 & 0.031 & 0.021 & 32 & 619 & 1,021 & 2,028 & 2,445 \\
\hline $30 \_49$ & $-0.041 * * *$ & 0.183 & 0.206 & 0.262 & 0.258 & 0.245 & 112 & 194 & 181 & 86 & 346 \\
\hline $50 \_69$ & $-0.105 * * *$ & 0.100 & 0.113 & 0.126 & 0.148 & 0.157 & -287 & -910 & -608 & -565 & -544 \\
\hline 70_89 & $-0.149 * * *$ & 0.030 & 0.045 & 0.054 & 0.077 & 0.087 & -86 & -356 & $-1,168$ & -695 & $-1,575$ \\
\hline \multicolumn{12}{|l|}{ Males } \\
\hline 10_29 & $0.005 * *$ & 0.192 & 0.153 & 0.104 & 0.067 & 0.040 & 76 & 373 & 338 & 814 & 1,547 \\
\hline 30_49 & $-0.022^{* * *}$ & 0.177 & 0.185 & 0.211 & 0.200 & 0.213 & 64 & 135 & 109 & -34 & 129 \\
\hline $50 \_69$ & $-0.084 * * *$ & 0.100 & 0.112 & 0.127 & 0.149 & 0.162 & -215 & -466 & -173 & -108 & -165 \\
\hline 70_89 & $-0.138 * * *$ & 0.022 & 0.038 & 0.048 & 0.069 & 0.076 & -44 & $-1,208$ & $-1,015$ & -292 & -202 \\
\hline \multicolumn{12}{|l|}{ Region } \\
\hline coastal-urban & $0.010^{* *}$ & 0.099 & 0.107 & 0.107 & 0.122 & 0.114 & -38 & -304 & -121 & 634 & 5 \\
\hline coastal - rural & $0.023^{* * *}$ & 0.240 & 0.243 & 0.241 & 0.238 & 0.234 & 111 & 482 & 571 & 323 & 191 \\
\hline inland - urban & $-0.006 * * *$ & 0.205 & 0.203 & 0.210 & 0.214 & 0.225 & -123 & -915 & -820 & $-1,207$ & -880 \\
\hline inland - rural & Reference & 0.456 & 0.447 & 0.443 & 0.426 & 0.427 & -1 & 172 & 24 & 28 & 150 \\
\hline \multicolumn{12}{|c|}{ Equivalent income/1,000 } \\
\hline linear & 3.442E-03*** & & & & & & & & & & \\
\hline quadratic & $-1.486 \mathrm{E}-04^{* *}$ & & & & & & & & & & \\
\hline cubic & $2.247 \mathrm{E}-06^{* *}$ & & & & & & & & & & \\
\hline Constant & $0.832^{* * *}$ & & & & & & & & & & \\
\hline
\end{tabular}

Note: Results are obtained after applying inverse probability weights (IPW) to equations (4) and (5).

$* \mathrm{p}<0.1, * * \mathrm{p}<0.05, * * * \mathrm{p}<0.01$

a. Number of observations in pooled interval regions is 42,542 ; the division over the waves can be found in table 2

b. Model statistics: Wald chi $(13)=2,712(P<0.0001)$ LR cubic/quadratic income $=23.48(P<0.0001)$

c. $\left(z_{i t} / n_{t}^{k}\right)-\left(z_{i 1} / n_{1}^{k}\right)$ equals the difference between the average weight $z_{i t}$ for age-sex/region category $k$ in periods $t$ and 1 . 


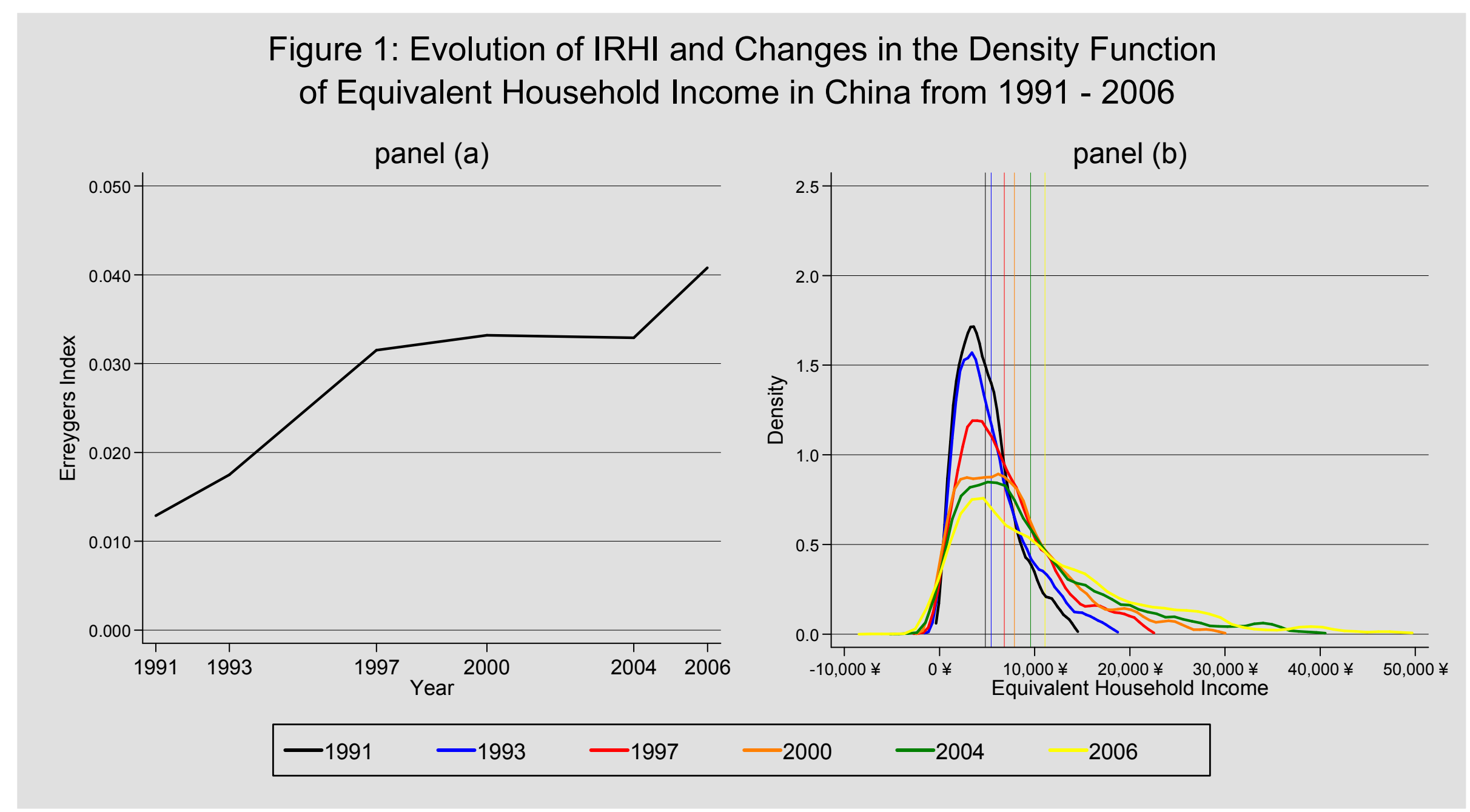

Note: the vertical bars in panel (b) represent the average equivalent income levels per wave; results are obtained after applying inverse probability weights (IPW) to equations (4) and (5). 


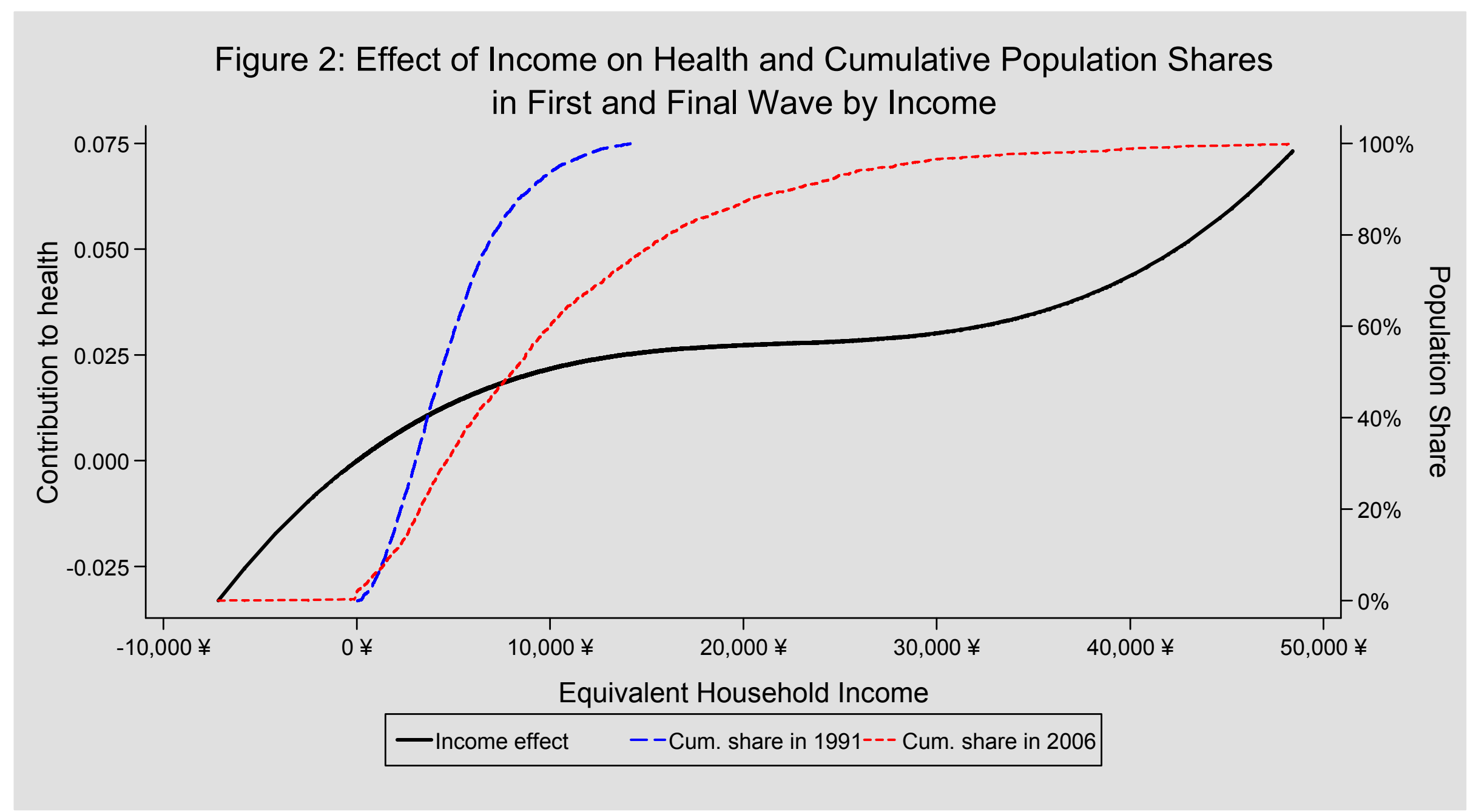

Note: results are obtained after applying inverse probability weights (IPW) to equations (4) and (5). 


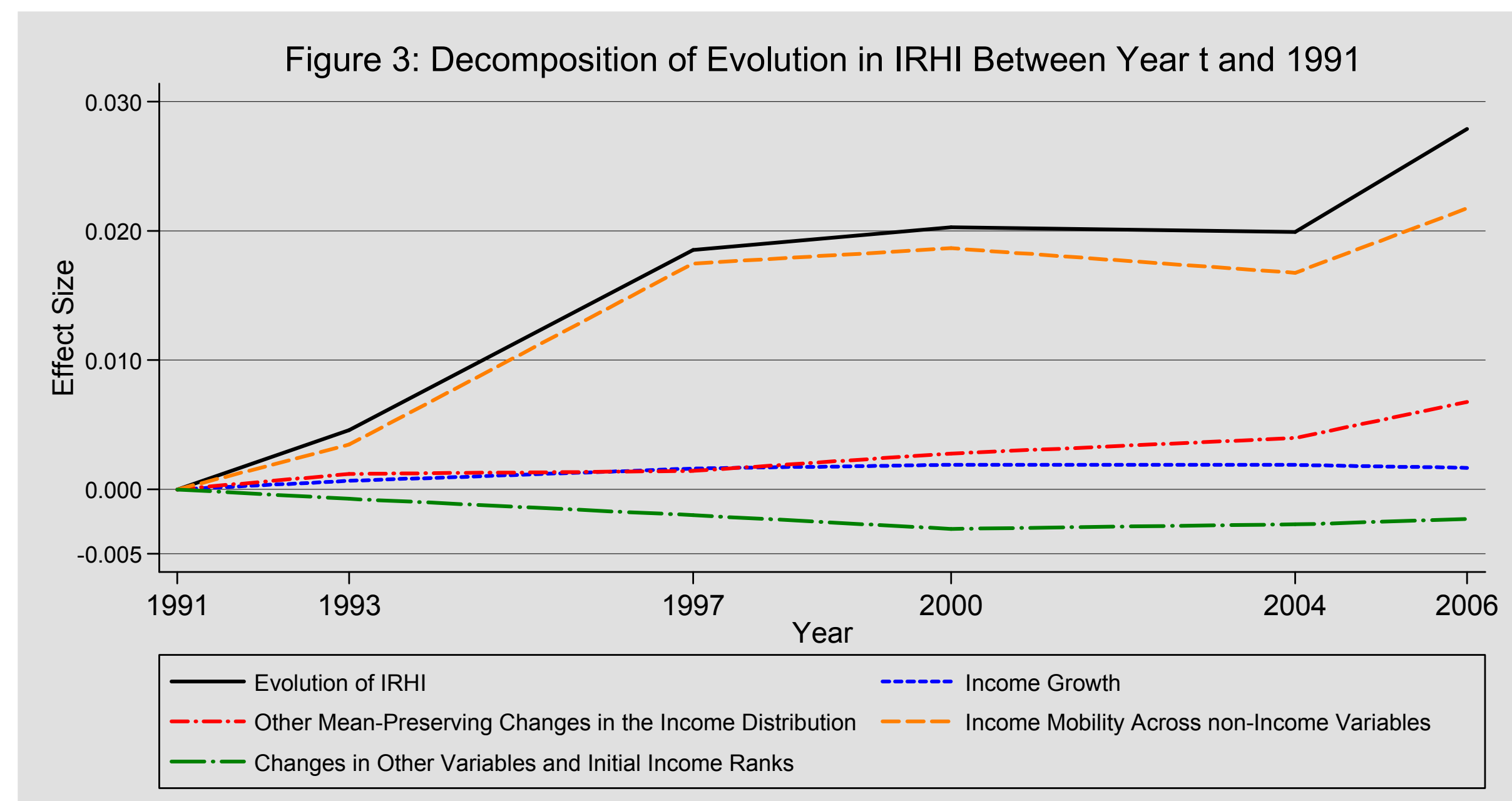

Note: statistical inference of the decomposition is provided in table A.2; results are obtained after applying inverse probability weights (IPW) to equations (4) and (5). 
Figure 4: Differences in Income Mobility Across Age, Sex and Region (panel a) and Differences in non-Income variables Across Initial Income (panel b)
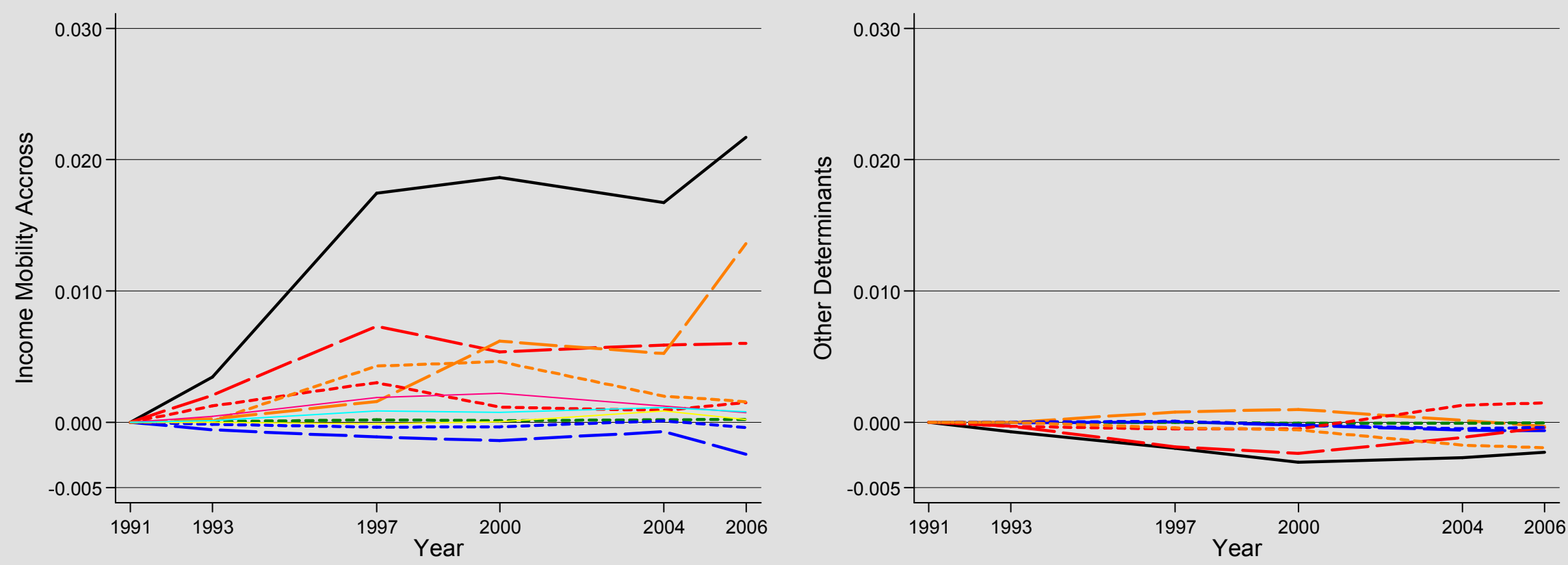

\begin{tabular}{|c|c|c|c|}
\hline — Total effect & ——Females 30-49 & ——Females 50-69 & $-\longrightarrow$ Females $70-89$ \\
\hline - Males 10-29 & -------- Males 30-49 & -- & - Males 70-89 \\
\hline Coastal urban & Coastal rural & Inland urban & \\
\hline
\end{tabular}

Note: statistical inference is provided in table A.2; results are obtained after applying inverse probability weights (IPW) to equations (4) and (5). 


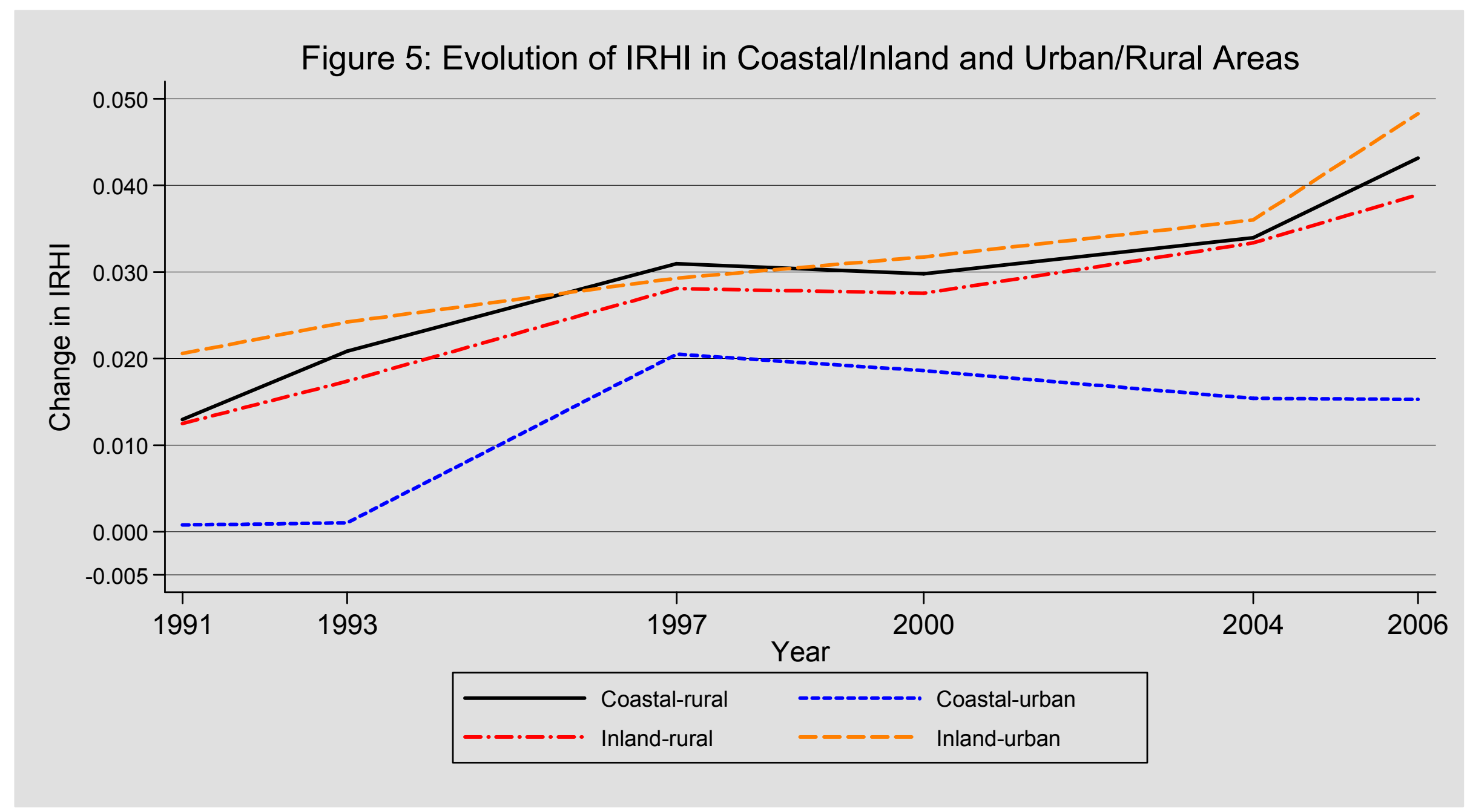

Note: results are obtained after applying inverse probability weights (IPW) to equations (4) and (5). Statistical inference is described in the text. More details can be obtained from the authors 


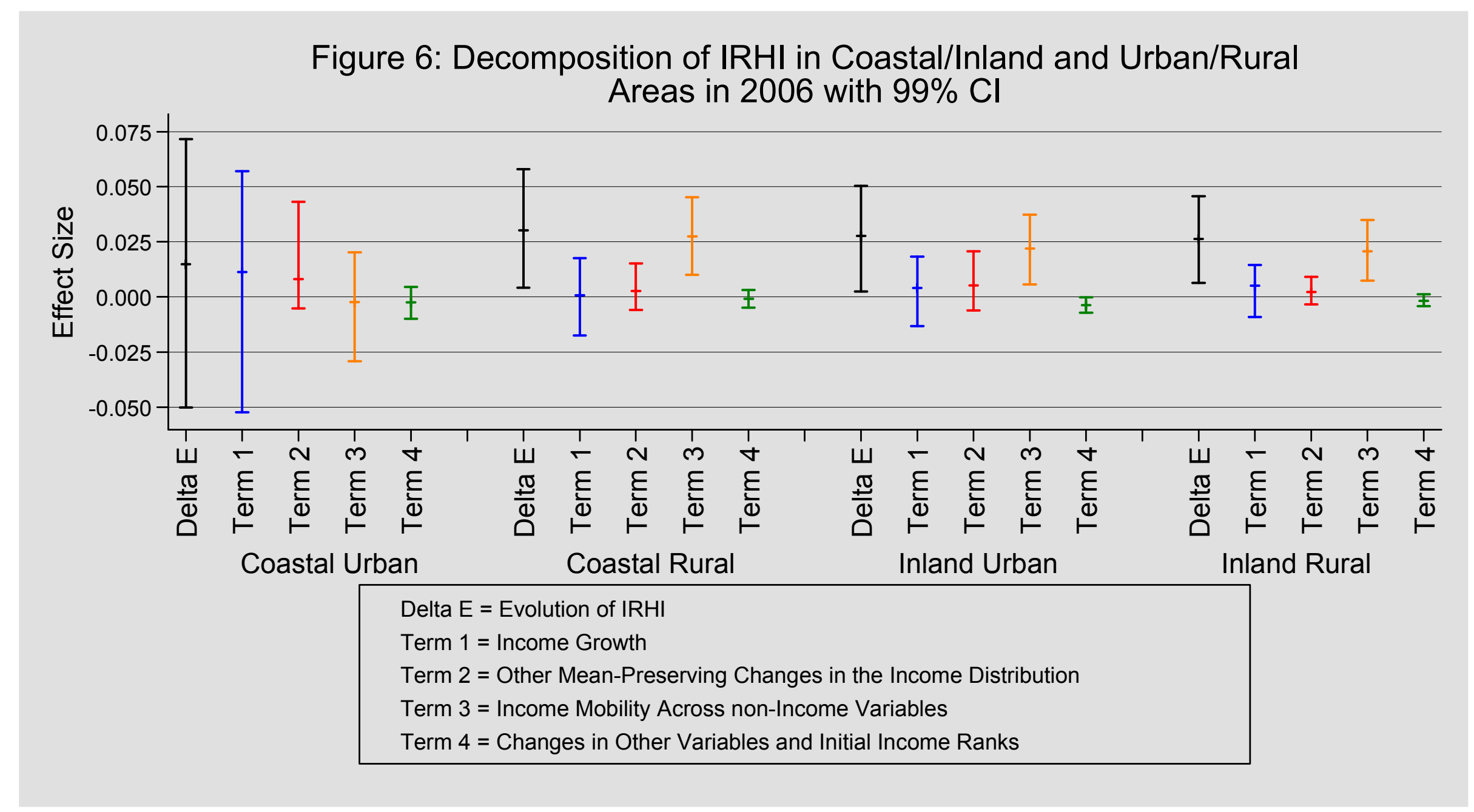

Note: results are obtained after applying inverse probability weights (IPW) to equations (4) and (5). 
A. 1: Probit models of the probability to be in wave $t$ conditional on wave 1 characteristics

\begin{tabular}{|c|c|c|c|c|c|c|c|c|c|c|}
\hline \multirow[b]{2}{*}{ Variable } & \multicolumn{2}{|c|}{1993} & \multicolumn{2}{|c|}{1997} & \multicolumn{2}{|c|}{2000} & \multicolumn{2}{|c|}{2004} & \multicolumn{2}{|c|}{2006} \\
\hline & coef & p-value & coef & p-value & coef & p-value & coef & p-value & coef & $\mathrm{p}$-value \\
\hline \multicolumn{11}{|l|}{ Females } \\
\hline 10_29 & Reference & Reference & Reference & Reference & Reference & Reference & Reference & Reference & Reference & Reference \\
\hline 30_49 & 0.674 & 0.000 & 0.739 & 0.000 & 1.118 & 0.000 & 1.274 & 0.000 & 1.226 & 0.000 \\
\hline 50_69 & 0.422 & 0.000 & 0.552 & 0.000 & 0.723 & 0.000 & 0.857 & 0.000 & 0.791 & 0.000 \\
\hline 70_89 & -0.030 & 0.730 & -0.008 & 0.921 & -0.055 & 0.520 & -0.226 & 0.020 & -0.439 & 0.000 \\
\hline \multicolumn{11}{|l|}{ Males } \\
\hline 10_29 & 0.250 & 0.000 & 0.282 & 0.000 & 0.255 & 0.000 & 0.331 & 0.000 & 0.276 & 0.000 \\
\hline 30_49 & 0.558 & 0.000 & 0.680 & 0.000 & 0.907 & 0.000 & 1.117 & 0.000 & 1.086 & 0.000 \\
\hline 50_69 & 0.380 & 0.000 & 0.455 & 0.000 & 0.644 & 0.000 & 0.759 & 0.000 & 0.633 & 0.000 \\
\hline 70_89 & -0.110 & 0.261 & -0.113 & 0.223 & -0.218 & 0.036 & -0.465 & 0.000 & -1.100 & 0.000 \\
\hline \multicolumn{11}{|l|}{ Region } \\
\hline Coastal-urban & -0.268 & 0.000 & -1.049 & 0.000 & -0.277 & 0.000 & -0.516 & 0.000 & -0.500 & 0.000 \\
\hline Coastal-rural & 0.129 & 0.001 & -0.584 & 0.000 & 0.002 & 0.958 & -0.073 & 0.021 & -0.100 & 0.002 \\
\hline Inland-urban & -0.233 & 0.000 & -0.217 & 0.000 & -0.086 & 0.010 & -0.179 & 0.000 & -0.247 & 0.000 \\
\hline Inland-rural & Reference & Reference & Reference & Reference & Reference & Reference & Reference & Reference & Reference & Reference \\
\hline \multicolumn{11}{|l|}{ Income } \\
\hline linear & $4.852 \mathrm{E}-01$ & 0.002 & 1.757E-01 & 0.017 & $-1.862 \mathrm{E}-02$ & 0.000 & $8.328 \mathrm{E}-02$ & 0.267 & $-9.428 \mathrm{E}-02$ & 0.000 \\
\hline quadratic & $-2.174 \mathrm{E}-01$ & 0.001 & $-7.389 \mathrm{E}-02$ & 0.001 & & & $-5.136 \mathrm{E}-02$ & 0.022 & $5.694 \mathrm{E}-03$ & 0.000 \\
\hline cubic & $3.758 \mathrm{E}-02$ & 0.003 & $8.920 \mathrm{E}-03$ & 0.000 & & & $6.524 \mathrm{E}-03$ & 0.010 & & \\
\hline power four & $-2.870 \mathrm{E}-03$ & 0.005 & $-3.320 \mathrm{E}-04$ & 0.000 & & & $-2.467 \mathrm{E}-04$ & $9.739 \mathrm{E}-03$ & & \\
\hline power five & $8.015 \mathrm{E}-05$ & 0.008 & & & & & & & & \\
\hline \multicolumn{11}{|l|}{ SAH response } \\
\hline Excellent & Reference & Reference & Reference & Reference & Reference & Reference & Reference & Reference & Reference & Reference \\
\hline Good & 0.019 & 0.673 & 0.034 & 0.358 & 0.003 & 0.939 & 0.052 & 0.172 & 0.028 & 0.466 \\
\hline Fair & -0.019 & 0.724 & -0.003 & 0.946 & -0.025 & 0.563 & -0.008 & 0.852 & -0.026 & 0.560 \\
\hline Poor & -0.418 & 0.000 & -0.420 & 0.000 & -0.420 & 0.000 & -0.420 & 0.000 & -0.383 & 0.000 \\
\hline Constant & 0.618 & 0.000 & 0.124 & 0.156 & -0.486 & 0.000 & -0.656 & 0.000 & -0.477 & 0.000 \\
\hline
\end{tabular}


A.2: Decomposition Results

\begin{tabular}{|c|c|c|c|c|c|c|}
\hline Variable & 1991 & 1993 & 1997 & 2000 & 2004 & 2006 \\
\hline $\mathrm{N}$ & 11,577 & 9,829 & 6,745 & 5,254 & 4,652 & 4,486 \\
\hline Average Health & 0.8119 & 0.809 & 0.8031 & 0.7957 & 0.7868 & 0.7837 \\
\hline Erreygers & $\begin{array}{c}0.013 \\
(0.0049 ; 0.0222)\end{array}$ & $\begin{array}{c}0.0175 \\
(0.0082 ; 0.0260)\end{array}$ & $\begin{array}{c}0.0315 \\
(0.0211 ; 0.0402)\end{array}$ & $\begin{array}{c}0.0332 \\
(0.0237 ; 0.0415)\end{array}$ & $\begin{array}{c}0.0329 \\
(0.0169 ; 0.0459)\end{array}$ & $\begin{array}{c}0.0408 \\
(0.0222 ; 0.0556)\end{array}$ \\
\hline IRHI change w.r.t. 1991 & & $\begin{array}{c}0.0046 \\
(-0.0011 ; 0.0086)\end{array}$ & $\begin{array}{c}0.0185 \\
(0.0105 ; 0.0252)\end{array}$ & $\begin{array}{c}0.0203 \\
(0.0114 ; 0.0277)\end{array}$ & $\begin{array}{c}0.0199 \\
(0.0053 ; 0.0331)\end{array}$ & $\begin{array}{c}0.0278 \\
(0.0100 ; 0.0432)\end{array}$ \\
\hline \multicolumn{7}{|l|}{ Main Effects } \\
\hline $\begin{array}{l}\text { Other Mean preserving Changes in } \\
\text { the Income Distribution }\end{array}$ & & $\begin{array}{c}0.0012 \\
(0.0004 ; 0.0024)\end{array}$ & $\begin{array}{c}0.0014 \\
(0.0005 ; 0.0039)\end{array}$ & $\begin{array}{c}0.0028 \\
(0.0005 ; 0.0077)\end{array}$ & $\begin{array}{c}0.0040 \\
(-0.0018 ; 0.0159)\end{array}$ & $\begin{array}{c}0.0068 \\
(0.0005 ; 0.0158)\end{array}$ \\
\hline $\begin{array}{l}\text { Income Mobility Across non- } \\
\text { Income Variables }\end{array}$ & & $\begin{array}{c}0.0034 \\
(-0.0015 ; 0.0078)\end{array}$ & $\begin{array}{c}0.0174 \\
(0.0111 ; 0.0245)\end{array}$ & $\begin{array}{c}0.0186 \\
(0.0111 ; 0.0257)\end{array}$ & $\begin{array}{c}0.0167 \\
(0.0085 ; 0.0249)\end{array}$ & $\begin{array}{c}0.0217 \\
(0.0090 ; 0.0358)\end{array}$ \\
\hline Income Growth & & $\begin{array}{c}0.0007 \\
(-0.0011 ; 0.0014)\end{array}$ & $\begin{array}{c}0.0016 \\
(-0.0036 ; 0.0041)\end{array}$ & $\begin{array}{c}0.0019 \\
(-0.0049 ; 0.0058)\end{array}$ & $\begin{array}{c}0.0019 \\
(-0.0077 ; 0.0091)\end{array}$ & $\begin{array}{c}0.0017 \\
(-0.0113 ; 0.0132)\end{array}$ \\
\hline $\begin{array}{l}\text { Changes in Other Variables and } \\
\text { Initial Income Ranks }\end{array}$ & & $\begin{array}{c}-0.0007 \\
(-0.0015 ; 0.0000)\end{array}$ & $\begin{array}{c}-0.0020 \\
(-0.0032 ;-0.0007)\end{array}$ & $\begin{array}{c}-0.0031 \\
(-0.0047 ;-0.0016)\end{array}$ & $\begin{array}{c}-0.0027 \\
(-0.0045 ;-0.0009)\end{array}$ & $\begin{array}{c}-0.0023 \\
(-0.0039 ;-0.0007)\end{array}$ \\
\hline \multicolumn{7}{|c|}{ Contributions of Individual Variables to Income Mobility Across non-Income Variables } \\
\hline \multicolumn{7}{|l|}{ Females } \\
\hline 10_29 & & Reference & Reference & Reference & Reference & Reference \\
\hline 30_49 & & $\begin{array}{c}-0.0006 \\
(-0.0014 ; 0.0002)\end{array}$ & $\begin{array}{c}-0.0011 \\
(-0.0025 ; 0.0002)\end{array}$ & $\begin{array}{c}-0.0014 \\
(-0.0033 ; 0.0003)\end{array}$ & $\begin{array}{c}-0.0007 \\
(-0.0030 ; 0.0016)\end{array}$ & $\begin{array}{c}-0.0025 \\
(-0.0052 ; 0.0006)\end{array}$ \\
\hline 50_69 & & $\begin{array}{c}0.0021 \\
(-0.0003 ; 0.0041)\end{array}$ & $\begin{array}{c}0.0073 \\
(0.0047 ; 0.0101)\end{array}$ & $\begin{array}{c}0.0054 \\
(0.0025 ; 0.0081)\end{array}$ & $\begin{array}{c}0.0059 \\
(0.0030 ; 0.0090)\end{array}$ & $\begin{array}{c}0.0060 \\
(0.0024 ; 0.0101)\end{array}$ \\
\hline 70_89 & & $\begin{array}{c}0.0002 \\
(-0.0014 ; 0.0019)\end{array}$ & $\begin{array}{c}0.0016 \\
(-0.0011 ; 0.0044)\end{array}$ & $\begin{array}{c}0.0062 \\
(0.0023 ; 0.0105)\end{array}$ & $\begin{array}{c}0.0052 \\
(0.0002 ; 0.0100)\end{array}$ & $\begin{array}{c}0.0136 \\
(0.0072 ; 0.0213)\end{array}$ \\
\hline Males & & & & & & \\
\hline 10_29 & & $\begin{array}{c}0.0000 \\
(-0.0001 ; 0.0002)\end{array}$ & $\begin{array}{c}0.0002 \\
(0.0000 ; 0.0005)\end{array}$ & $\begin{array}{c}0.0001 \\
(0.0000 ; 0.0004)\end{array}$ & $\begin{array}{c}0.0002 \\
(0.0000 ; 0.0005)\end{array}$ & $\begin{array}{c}0.0002 \\
(0.0000 ; 0.0006)\end{array}$ \\
\hline
\end{tabular}


30_49

$50 \_69$

70_89

Region

$$
\begin{aligned}
& \text { inland - rural } \\
& \text { inland - urban } \\
& \text { coastal - rural } \\
& \text { coastal - urban }
\end{aligned}
$$

$-0.0002$

$(-0.0007 ; 0.0004)$

0.0012

$(-0.0004 ; 0.0027)$

0.0001

$(-0.0012 ; 0.0014)$
$-0.0004$

$(-0.0012 ; 0.0002)$

0.0030

$(0.0009 ; 0.0054)$

0.0043

(0.0009; 0.0092)
$-0.0004$

$(-0.0012 ; 0.0003)$

$$
0.0011
$$

$(-0.0009 ; 0.0035)$

0.0046

$(0.0007 ; 0.0084)$

Reference

0.0008

0.0001

$(-0.0006 ; 0.0009)$

0.0004

$(-0.0020 ; 0.0030)$

0.0000

$(-0.0011 ; 0.0006)$
$(-0.0007 ; 0.0030)$

0.0019

$(-0.0008 ; 0.0049)$

$-0.0001$

$(-0.0034 ; 0.0007)$
Reference

0.0007

0.0022

$(-0.0002 ; 0.0054)$

0.0000

$(-0.0022 ; 0.0010)$
$(-0.0006 ; 0.0033)$
0.0001

$(-0.0008 ; 0.0010)$

0.0009

$(-0.0015 ; 0.0034)$

0.0020

$(-0.0071 ; 0.0087)$

Reference

0.0011

$(-0.0009 ; 0.0037)$

$$
0.0012
$$

$(-0.0018 ; 0.0045)$

0.0008

$(-0.0012 ; 0.0031)$
$-0.0004$

$(-0.0018 ; 0.0010)$

0.0015

$(-0.0016 ; 0.0051)$

0.0016

$(-0.0206 ; 0.0202)$

Contributions of Individual Variables to Changes in Other Variables and Initial Income Ranks Females
$10 \_29$
30_49
$50 \_69$
$70 \_89$

Males

30_49

$50 \_69$

\section{Reference}

$-0.0001$

$(-0.0005 ; 0.0004)$

$-0.0003$

$(-0.0011 ; 0.0004$

0.0000

$(-0.0005 ; 0.0006)$

0.0000

$(-0.0001 ; 0.0000)$

0.0000

$(-0.0002 ; 0.0003)$

$-0.0003$
Reference

0.0000

$(-0.0008 ; 0.0009)$

$-0.0019$

$(-0.0034 ;-0.0004)$

0.0008

$(-0.0005 ; 0.0021)$

0.0000

$(-0.0001 ; 0.0001)$

0.0001

$(-0.0004 ; 0.0006)$

$-0.0005$

\section{Reference}

$-0.0002$

$(-0.0013 ; 0.0008)$

$-0.0024$

0.0010

$(-0.0007 ; 0.0026)$

$$
-0.0001
$$

$(-0.0003 ; 0.0000)$

$-0.0002$

$(-0.0009 ; 0.0004)$

$-0.0005$

\section{Reference}

$-0.0006$

$(-0.0021 ; 0.0007)$

$-0.0012$

$-0.0040 ; 0.0016$

0.0001

$(-0.0022 ; 0.0024)$

$$
-0.0001
$$

$(-0.0003 ; 0.0000)$

$-0.0005$

$(-0.0012 ; 0.0002)$

0.0013
Reference

0.0008

$(-0.0006 ; 0.0033)$

0.0007

$(-0.0027 ; 0.0038)$

0.0002

$(-0.0020 ; 0.0032)$ 

7089
$(-0.0011 ; 0.0004)$
$(-0.0020 ; 0.0009)$
$(-0.0025 ; 0.0013)$
$(-0.0011 ; 0.0036)$
$(-0.0011 ; 0.0041)$
0.0000
$-0.0004$
$-0.0006$
$-0.0018$
$-0.0019$

Note: $99 \%$ confidence intervals 